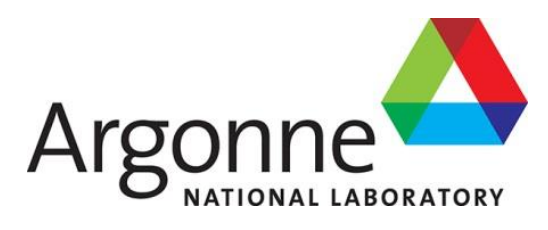

ANL- 21/36

\title{
An Overview of Argonne's Advanced Mobility Technology Laboratory Vehicle Systems Instrumentation and Evaluation Methodology
}

Revision: 2021-04-13

Energy Systems Division 


\section{About Argonne National Laboratory}

Argonne is a U.S. Department of Energy laboratory managed by UChicago Argonne, LLC under contract DE-AC02-06CH11357. The Laboratory's main facility is outside Chicago, at 9700 South Cass Avenue, Argonne, Illinois 60439. For information about Argonne and its pioneering science and technology programs, see www.anl.gov.

\section{DOCUMENT AVAILABILITY}

Online Access: U.S. Department of Energy (DOE) reports produced after 1991 and a growing number of pre-1991 documents are available free at OSTI.GOV (http://www.osti.gov/), a service of the US Dept. of Energy's Office of Scientific and Technical Information.

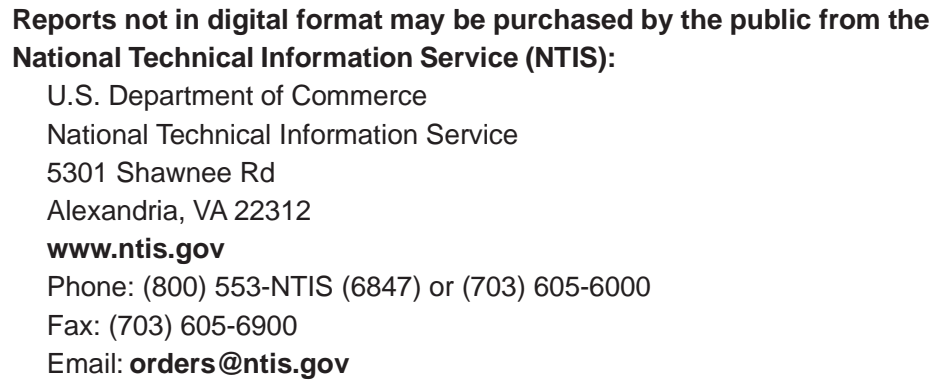

Reports not in digital format are available to DOE and DOE contractors from the Office of Scientific and Technical Information (OSTI):

U.S. Department of Energy

Office of Scientific and Technical Information

P.O. Box 62

Oak Ridge, TN 37831-0062

www.osti.gov

Phone: (865) 576-8401

Fax: (865) 576-5728

Email: reports@osti.gov

\section{Disclaimer}

This report was prepared as an account of work sponsored by an agency of the United States Government. Neither the United States Government nor any agency thereof, nor UChicago Argonne, LLC, nor any of their employees or officers, makes any warranty, express or implied, or assumes any legal liability or responsibility for the accuracy, completeness, or usefulness of any information, apparatus, product, or process disclosed, or represents that its use would not infringe privately owned rights. Reference herein to any specific commercial product, process, or service by trade name, trademark, manufacturer, or otherwise, does not necessarily constitute or imply its endorsement, recommendation, or favoring by the United States Government or any agency thereof. The views and opinions of document authors expressed herein do not necessarily state or reflect those of the United States Government or any agency thereof, Argonne National Laboratory, or UChicago Argonne, LLC. 


\section{An Overview of Argonne's Advanced Mobility Technology Laboratory Vehicle Systems Instrumentation and Evaluation Methodology}

Revision: 2021-04-13

prepared by:

Kevin Stutenberg,

Henning Lohse-Busch,

Mike Duoba

Simeon lliev,

Forrest Jehlik,

Miriam Di Russo

Energy Systems Division, Argonne National Laboratory

April 13, 2021 


\section{Table of contents}

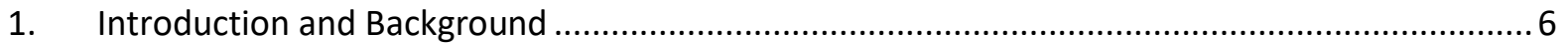

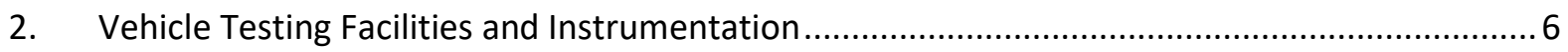

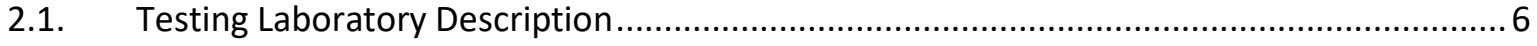

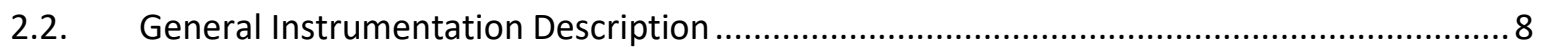

2.2.1. Purpose Built Data Acquisition System ...................................................................... 8

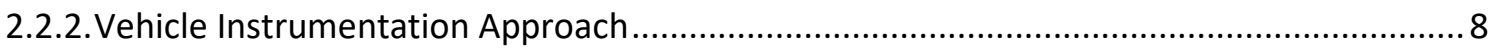

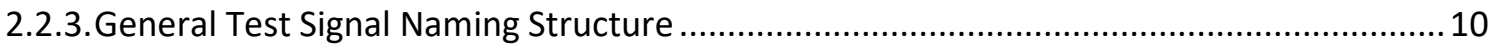

2.2.4. Fuel flow measurements (PFI, DI, Coriolis, Modal, Bag) .................................................. 12

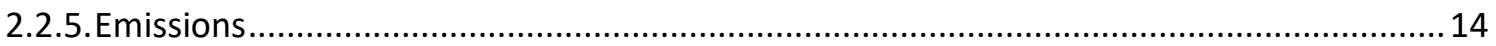

2.2.6. Electrical System Measurements- Low and High Voltage................................................ 14

2.2.7. Analog Vehicle Instrumentation- Temperatures and Flows ...............................................16

2.2.8. Vehicular Communication Systems Instrumentation ...................................................16

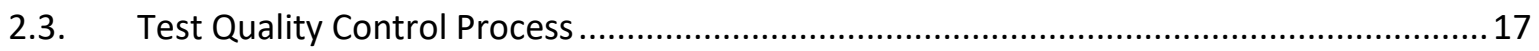

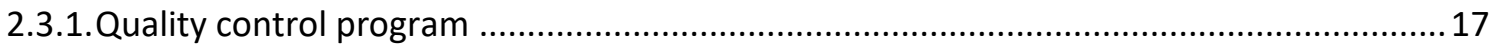

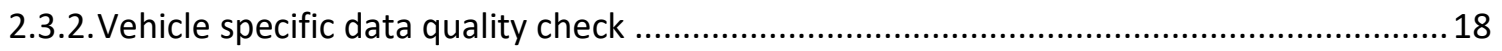

3. Research acquisition, preparation, and instrumentation ................................................... 19

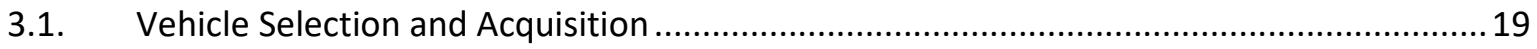

3.2. Vehicle Preparation Prior to Testing ......................................................................... 19

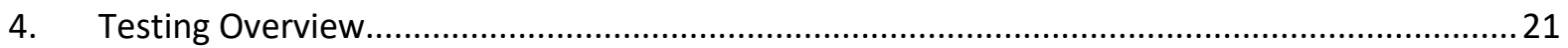

4.1. Argonne's approach to vehicle testing and differences to certification testing................21

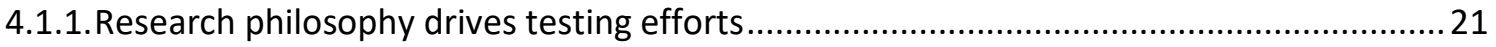

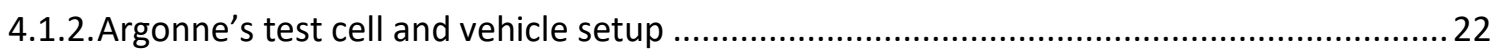

4.2. Vehicle Chassis Dynamometer Setup and Loss Determinations......................................23

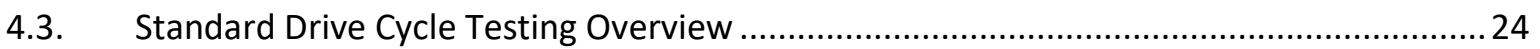

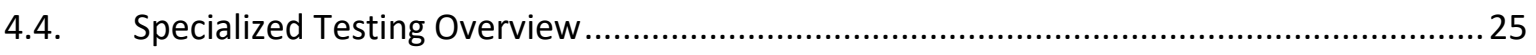

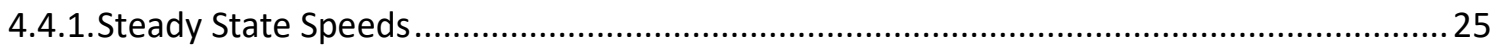

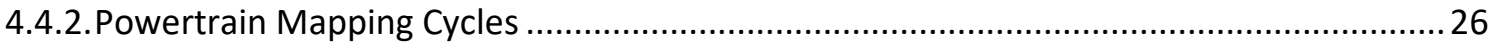

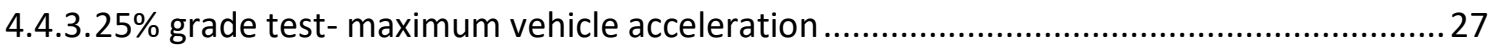

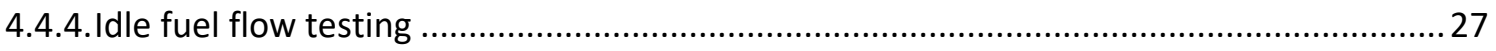

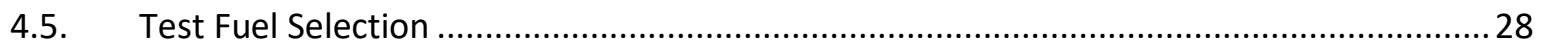

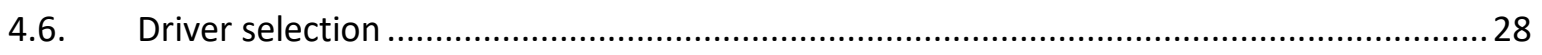

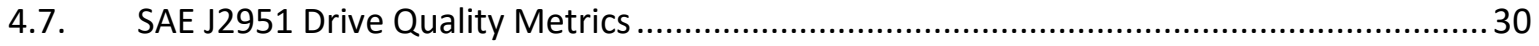

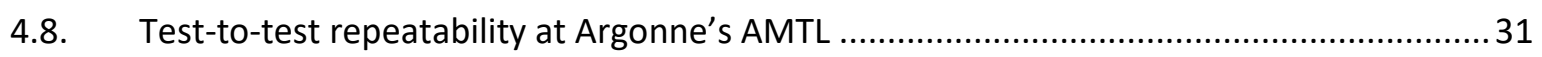

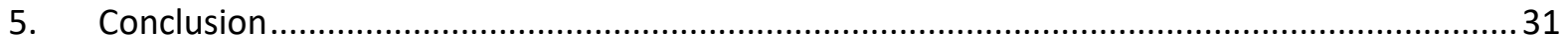

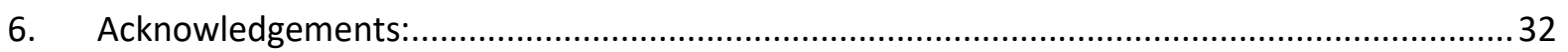

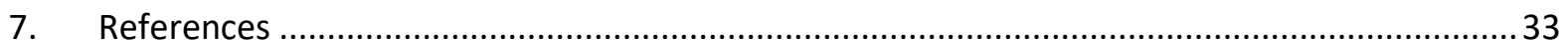

ANL-21/36: AMTL Vehicle Systems Instrumentation and Evaluation Methodology 


\section{Table of figures}

Figure 1: Major features of the 4WD chassis dynamometer and thermal chamber test cell............... 7

Figure 2: Major features of the 2WD chassis dynamometer and thermal chamber test cell................ 8

Figure 3: Overview of general instrumentation for a conventional vehicle ....................................... 9

Figure 4: Unique test identification number description .............................................................. 10

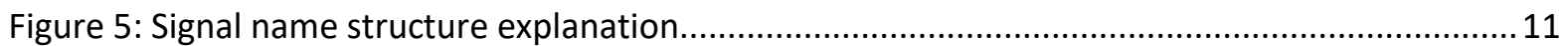

Figure 6: Instrumentation of Port and Direct Fuel Injection Systems on a 2018 Toyota Camry..........13

Figure 7: Direct Fuel Flow measurements via Fuel Scale and Coriolis flow meters ..........................13

Figure 8: Overview of example electrical instrumentation on a conventional vehicle (left), and

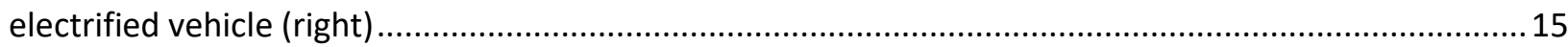

Figure 9: Example of a CAN Breakout point on a test vehicle ...................................................... 17

Figure 10: Drive cycle developed from on-road data for on dyno mileage accumulation...................20

Figure 11: Vehicle mounted for mileage accumulation on the AMTL 2WD chassis dynamometer. ...21

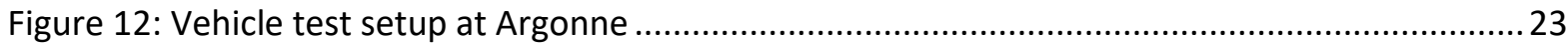

Figure 13: Daily drive cycle test sequence executed in the morning ...............................................24

Figure 14: Overview of single phase of the steady state drive cycle .............................................26

Figure 15: Vehicle Acceleration with varying constant pedal inputs ..............................................22

Figure 16: Constant acceleration ramp cycles with varying accelerator pedal inputs ........................27

Figure 17: Argonne custom robot driver installed in a vehicle ................................................29

Figure 18: A few select SAE J2951 drive quality metrics from a study comparing different drivers

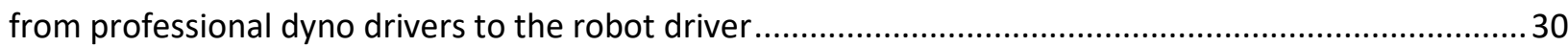

ANL-21/36: AMTL Vehicle Systems Instrumentation and Evaluation Methodology 


\section{Table of tables}

Table 1: Standard data streams collected at Argonne's Advanced Mobility Technology Laboratory ... 9

Table 2: Example of signal names

Table 3: Designator list of Power Analyzer Measurements .16

Table 4: Typical test plan for vehicle technology assessments. .25

Table 5: Main specifications of an example EPA Tier 3 EEE fuel .28

Table 6: Main specifications of an example EPA Tier 2 EEE fuel. .28

ANL-21/36: AMTL Vehicle Systems Instrumentation and Evaluation Methodology 


\section{Definitions and Abbreviations}

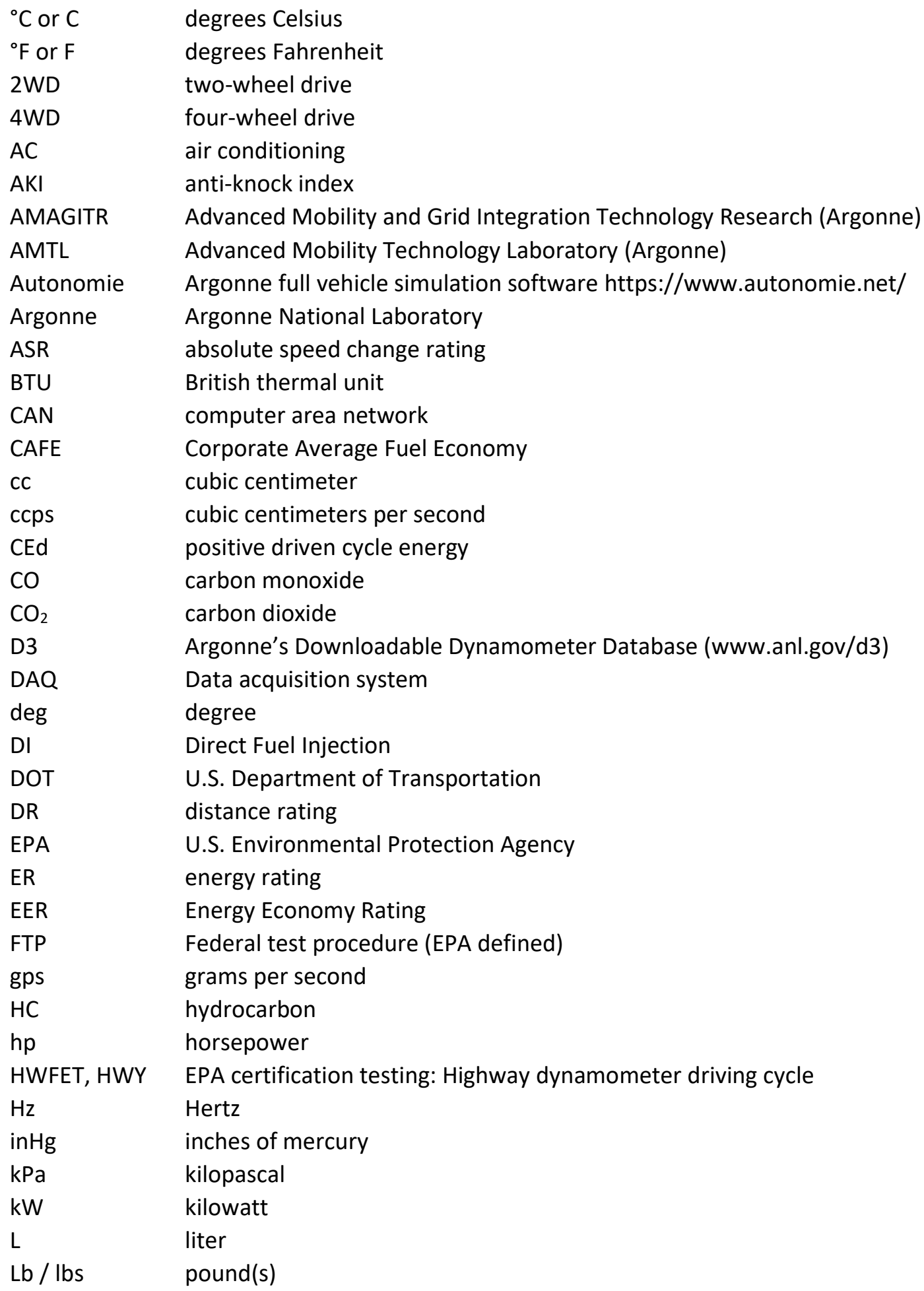

ANL-21/36: AMTL Vehicle Systems Instrumentation and Evaluation Methodology 


$\begin{array}{ll}\text { lb-ft } & \text { foot pounds } \\ \mathrm{lbm} & \text { pound-mass } \\ \mathrm{m} & \text { meter } \\ \mathrm{mg} & \text { milligrams } \\ \mathrm{mpg} & \text { mile(s) per gallon } \\ \mathrm{mph} & \text { miles per hour } \\ \mathrm{N} & \text { Newton } \\ \mathrm{NHTSA} & \text { National Highway Transportation Safety Administration } \\ \mathrm{Nm} & \text { Newton-meters (torque) } \\ \text { NOx } & \text { oxides of nitrogen } \\ \text { PFI } & \text { Port fuel injected } \\ \text { PHEV } & \text { Plug-in Hybrid Electric Vehicle } \\ \text { RMS } & \text { root mean squared error } \\ \text { rpm } & \text { rotations per minute } \\ \text { RWD } & \text { rear wheel drive } \\ \text { S } & \text { second } \\ \text { SAE } & \text { Society of Automotive Engineers } \\ \text { SC03 } & \text { EPA certification test (Air conditioning test) } \\ \text { SCfm } & \text { standard cubic feet per minute } \\ \text { SSS } & \text { steady speed stairs } \\ \text { UDDS } & \text { EPA certification test: urban dynamometer driving schedule } \\ \text { USO6 } & \text { EPA certification test: USO6 dynamometer driving schedule } \\ \text { V } & \text { Volts } \\ \text { W } & \text { Watt } \\ & \end{array}$

ANL-21/36: AMTL Vehicle Systems Instrumentation and Evaluation Methodology 


\section{Introduction and Background}

This report will provide a general overview of the testing facilities, research equipment, and general testing methodologies Argonne utilizes to conduct vehicle technology evaluations of advanced technology research vehicles. Data is captured from vehicle evaluations that provide powertrain operation and corresponding energy consumption based on a combination of in-depth instrumentation and focused testing. This resulting dataset of hundreds of time-resolved vehicle signals provide a basis for direct analysis and model validation of vehicle specific technologies.

Argonne has attempted to standardize the approach to vehicle instrumentation and testing at Argonne, but it should be noted that each vehicle, and the corresponding assessment, remains unique. It is suggested that the reader reference vehicle specific testing reports for an overview of the unique aspects for each test vehicle. Additionally, the datasets for research vehicles are made publicly available through the Advanced Mobility Technology Laboratory's Downloadable Driving Database (D3) at www.anl.gov/d3.

\section{Vehicle Testing Facilities and Instrumentation}

\subsection{Testing Laboratory Description}

Argonne National Laboratory has several research groups and facilities performing automotive research within the Center for Transportation Research. Vehicle testing discussed in this report is performed within the Advanced Mobility and Grid Integration Technology Research Group (AMAGITR), which provides resources for both vehicle instrumentation and testing. Within this research group, Argonne staff have been performing technology assessments of advanced technology vehicles since the late 1990s. The well-refined vehicle test process starts with instrumentation and testing and ends with detailed analysis of the results. The testing staff aim to understand the power (fuel or electric) flows between the components in the vehicle to characterize the behavior and establish transient efficiency and usage maps for key components of the powertrain.

Full vehicle testing for NHTSA project work is performed within one facility, referred to as the Advanced Mobility Technology Laboratory (AMTL), containing a 4WD chassis dynamometer housed within a thermal chamber. This 4WD test cell is designed to handle light- to medium-duty vehicles and includes a thermal chamber that is EPA five-cycle-capable with temperature variable from $-17^{\circ} \mathrm{C}$ to $35^{\circ} \mathrm{C}\left(0^{\circ} \mathrm{F}\right.$ to $\left.95^{\circ} \mathrm{F}\right)$. A vehicle speed-matching simulation fan fulfills the test regulations for the $\mathrm{SCO} 3$ air-conditioning test. The cell also contains solar lamps to simulate real-world solar loading of 850 $\mathrm{W} / \mathrm{m}^{2}$. Figure 1 highlights some of the broad capabilities of the 4WD test cell. 


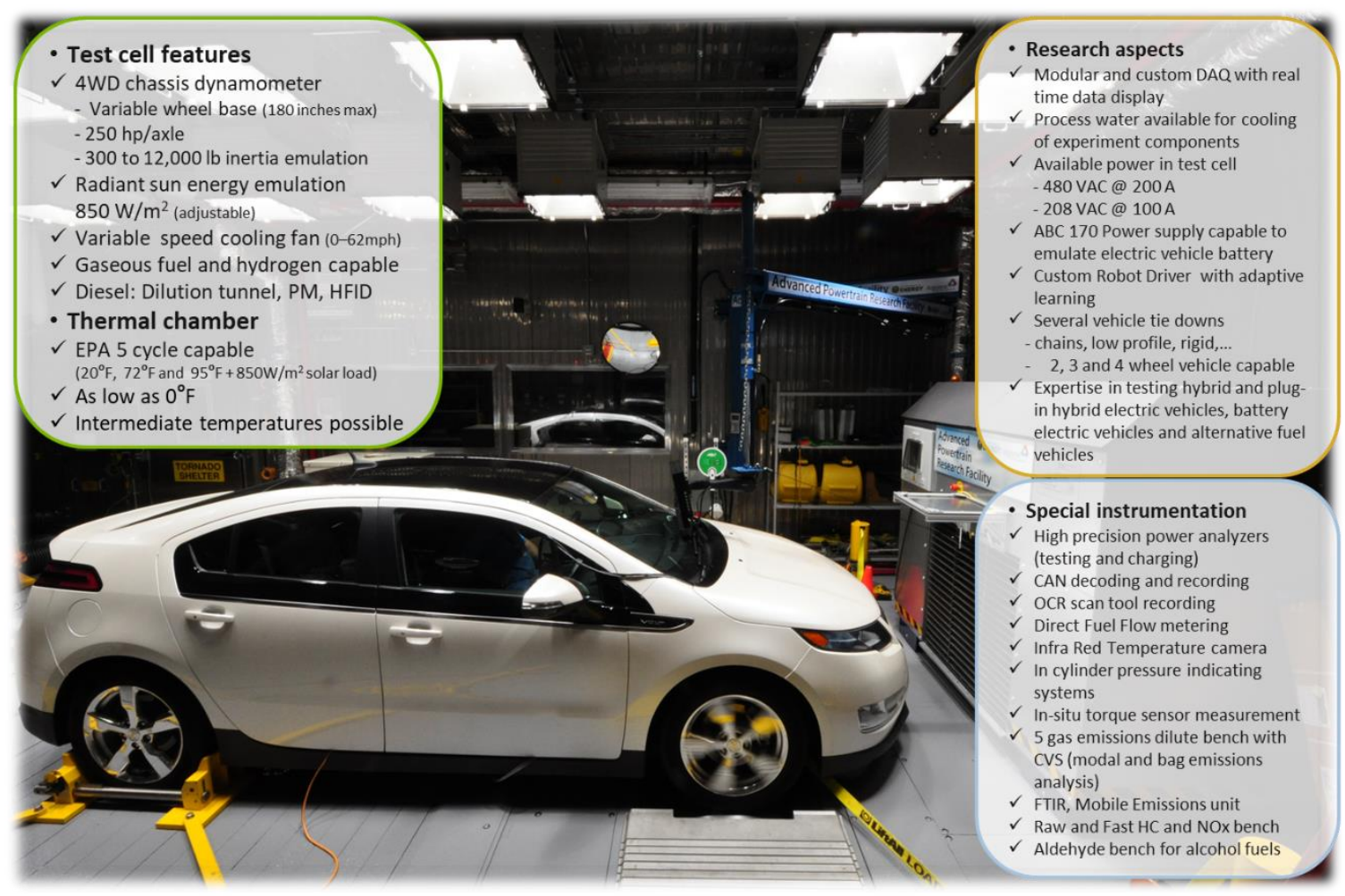

Figure 1: Major features of the 4WD chassis dynamometer and thermal chamber test cell.

An additional 2 WD chassis dynamometer testing facility acts as an additional resource for vehicle testing, with a large subset of the functionality of the 4WD test facility. The 2WD chassis dynamometer resides within a conditioned highbay, though the testing temperature is not variables as at the AMTL. Similar data acquisition system, available instrumentation, test schedules, and post processing routines are used across the 2WD and 4WD test facilities. Figure 2 below provides an overview of the 2 WD test facility. 


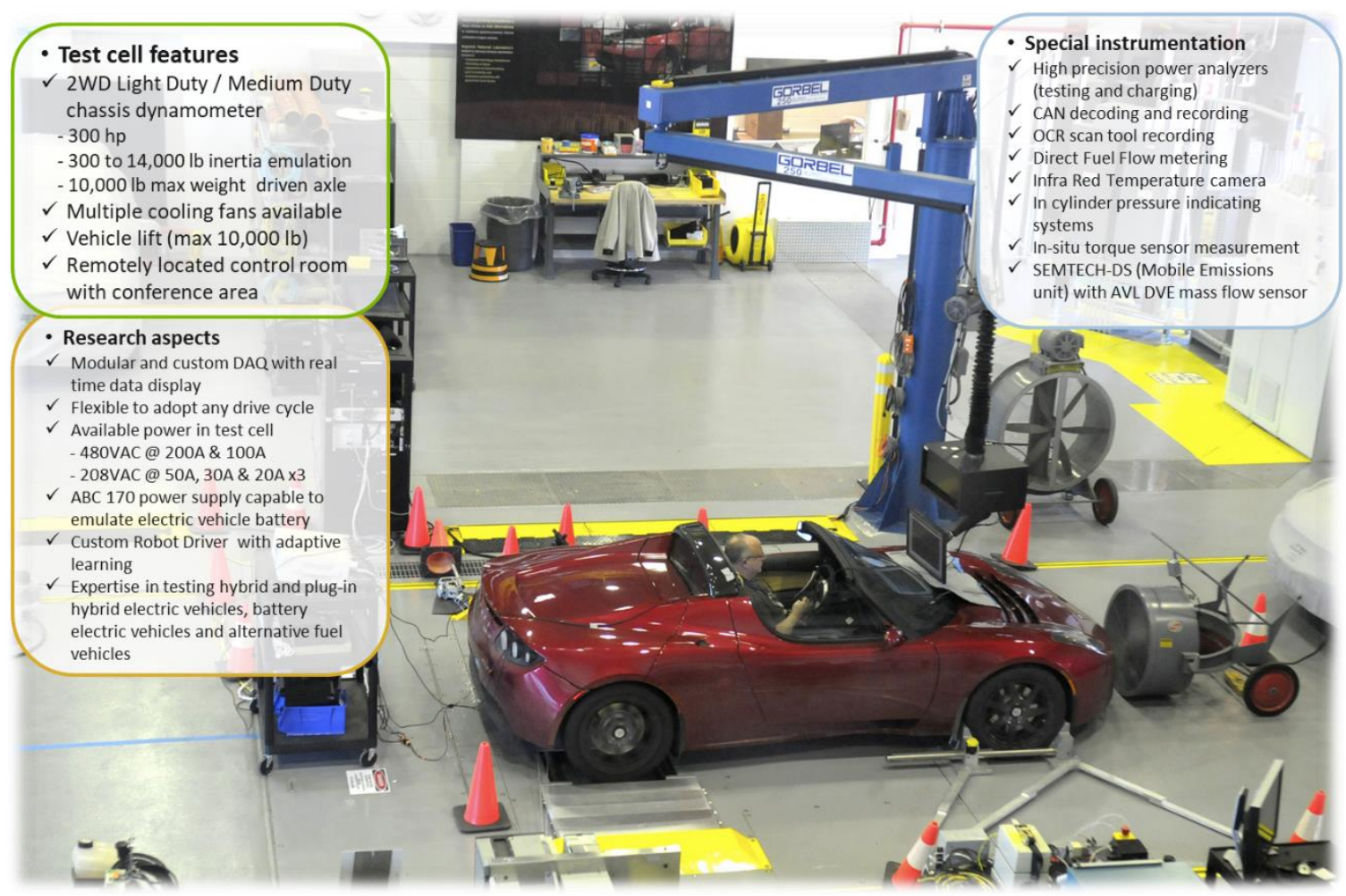

Figure 2: Major features of the 2WD chassis dynamometer and thermal chamber test cell.

\subsection{General Instrumentation Description}

\subsubsection{Purpose Built Data Acquisition System}

The AMTL staff developed and refined a custom modular host and data acquisition system for use in both chassis dynamometer test facilities. The system manages the varying instrumentation, the facility equipment, data collection, and post processing. This custom data acquisition (DAQ) is built in a National Instruments LabVIEW environment that merges and time aligns data streams from many different selectable sources. These data sources include facility sensors, dynamometer feedback, analog vehicle sensors, vehicle communication messaging, emissions analyzers, fuel flow meters, electrical power analyzers, and many others.

A particular benefit of the custom built DAQ is the ability to display real time signals from any sensor in the instrumentation. This enables targeted component mapping as the testing staff can set and verify component operating points, perform quality control checks in real-time, vary test conditions, and ensure that all relevant signals have reached stability in real time. This capability ensures quality data for later component characterization and modeling. Further details of the methods for vehicle instrumentation are presented within the next section of this report.

\subsubsection{Vehicle Instrumentation Approach}

The AMTL is a purpose-built facility for automotive systems research and technology benchmarking. Based on that mission, the staff have developed a unique expertise focused on the

ANL-21/36: AMTL Vehicle Systems Instrumentation and Evaluation Methodology 
instrumentation of advanced technology powertrain components. This expertise includes: decoding and capture of vehicle broadcast CAN and diagnostic messages, in-situ component mapping instrumentation, a flexible facility architecture, and the custom data acquisition system. Additionally, the staff have developed unique test procedures to produce desired high quality research results.

Figure 3 illustrates the general instrumentation of research vehicles. Due to the capture of data from multiple unique pieces of measurement equipment, a central DAQ is used to combine and time align data streams. Vehicle and powertrain specific data is captured from mixture of analog and digital instrumentation systems. General analog vehicle signals are part of the standard testing and typically include engine oil temperature, direct fuel flow measurements, and electric power flow measurements (both low and high voltage). Digital vehicle instrumentation includes an extensive list of signals decoded from broadcast or diagnostic vehicle communication messages.

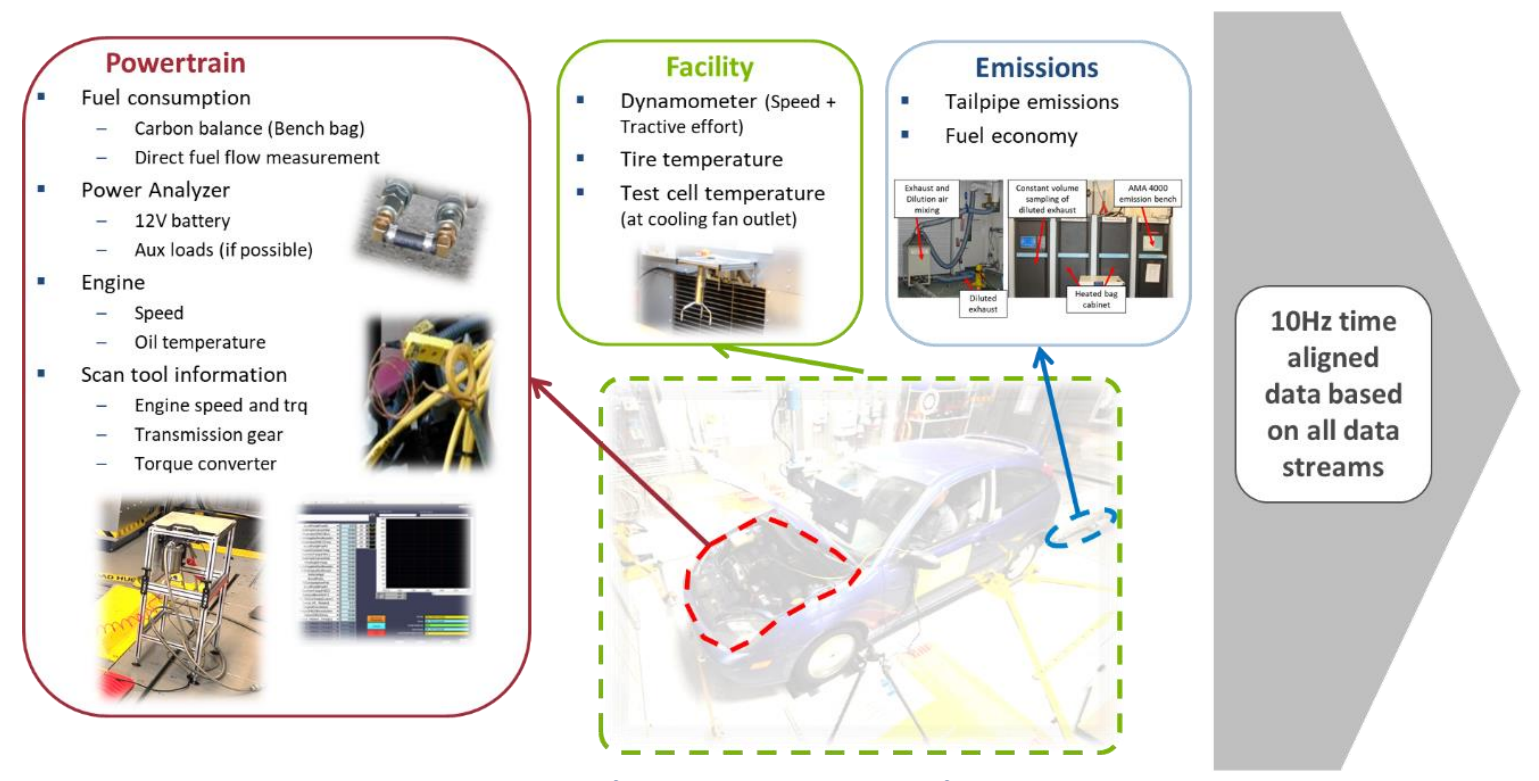

Figure 3: Overview of general instrumentation for a conventional vehicle

Facility data is data captured from non-vehicle specific measurements systems within the test cell to understand the surrounding testing environment. This data includes test cell conditions (ambient test cell temperature and relative humidity), dynamometer data (vehicle speed and the tractive effort) and emissions data (bag and modal bench data: $\mathrm{HC}, \mathrm{CO}, \mathrm{NOx}$, and $\mathrm{CO}_{2}$ ). Additionally, the data acquisition system records test specific management data, such as the target drive schedule and phase information.

Table 1 shows what the "standard stream" of data typically includes. Additionally, many more signals are generally captured which are dependent on the specific research vehicle. This full list of signals can be found in each specific vehicle testing report.

Table 1: Standard data streams collected at Argonne's Advanced Mobility Technology Laboratory

ANL-21/36: AMTL Vehicle Systems Instrumentation and Evaluation Methodology 


\begin{tabular}{|l|l|l|l|}
\hline Facility data & Drive cycle input & Emissions data & Generic vehicle data \\
\hline Dyno_Spd[mph] & Drive_Schedule_Time[s] & Dilute_CH4[mg/s] & Engine_Oil_Dipstick_Temp[C] \\
\hline Dyno_TractiveForce[N] & Drive_Trace_Schedule[mph] & Dilute_NOx[mg/s] & Cabin_Temp[C] \\
\hline Dyno_LoadCell[N] & Exhaust_Bag [] & Dilute_COlow[mg/s] & Solar_Array_Ind_Temp[C] \\
\hline DilAir_RH[\%] & & Dilute_COmid[mg/s] & Eng_FuelFlow_Direct[gps] \\
\hline Tailpipe_Press[inH2O] & & Dilute_CO2[mg/s] & Eng_FuelFlow_Direct[ccps] \\
\hline Cell_Temp[C] & & Dilute_HFID[mg/s] & 12V Battery [V], [A] and [W] \\
\hline Cell_RH[\%] & Dilute_NMHC[mg/s] & \\
\hline Cell_Press[inHg] & & Dilute_Fuel[g/s] & \\
\hline Tire_Rear_Temp[C] & & & \\
\hline Tire_Front_Temp[C] & & & \\
\hline
\end{tabular}

\subsubsection{General Test Signal Naming Structure}

Explanation of unique identification number for each test

Each vehicle test preformed on a chassis dynamometer at Argonne has a unique test identification number which can be referenced in distributed test datasets. The number includes the following information about the test: test cell location, calendar year, month, and unique test number within the month. Figure 4 explains the structure of the test identification number.

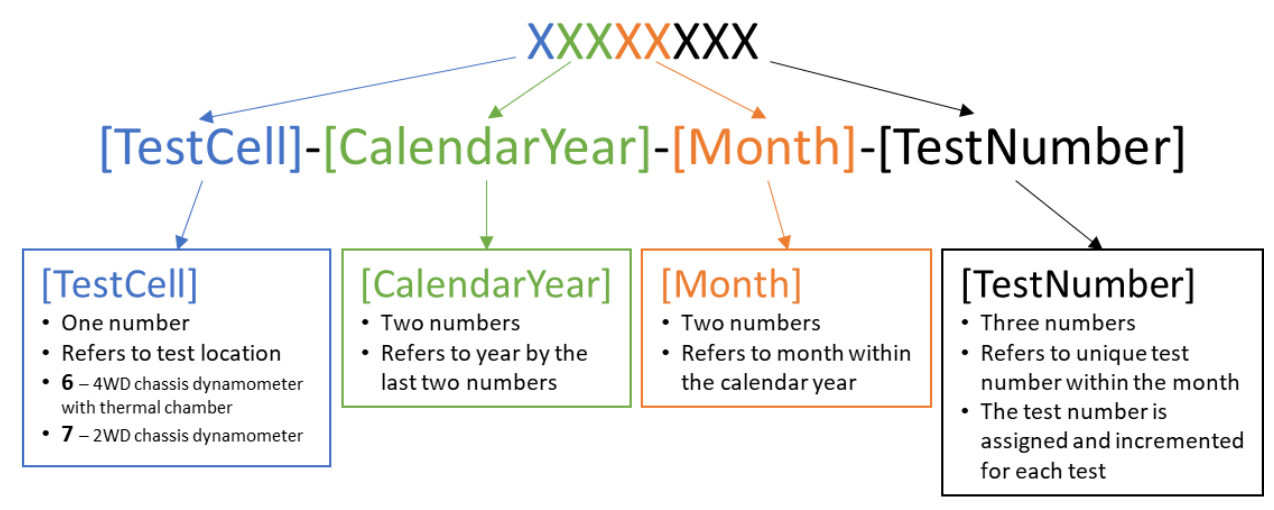

Figure 4: Unique test identification number description

An example identification number of 61907045 would translate to: this test is the $45^{\text {th }}$ test, of the $7^{\text {th }}$ month of the year (July), in 2019, performed in test cell \# 6 (the 4WD chassis dynamometer). Though all testing within this program is completed within test cell \#6, test cell \#7 (the 2WD chassis dynamometer) may occasionally be used for mileage accumulation and preliminary testing resulting in listed test ID's.

\section{Signal name explanation}

The team attempts to use a standard naming structure for each recorded signal whenever possible. In many cases the specific signal or sensor may be unique, and not fit within that structure. In these cases, the team will modify the structure but try to keep the name understandable to experts in the field.

ANL-21/36: AMTL Vehicle Systems Instrumentation and Evaluation Methodology 
The standard structure starts with the major component of which the signal relates. Next, the signal is identified in the structure. Following this, a few optional quantifiers maybe used such as an instrument or a location or direction. The final part of the signal name is the unit of the measurement, listed either in brackets "[]", or following a double underscore "_".

The components of the signal names often use abbreviated words to keep the overall length of the final signal names from becoming too long. When the signal is sourced from the vehicle communication bus, the original name of the originating CAN bus may be used. When the signal is sourced from a diagnostic message, an acronym for the originating controller is commonly used. An example would be PCM for Powertrain Control Module. Figure 5 provides a visual explanation of the signal naming structure.

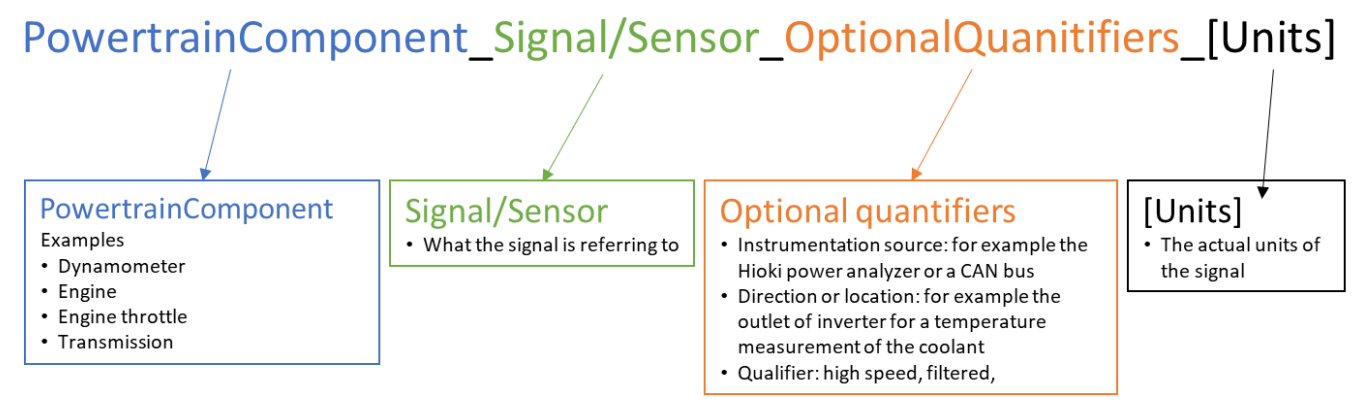

Figure 5: Signal name structure explanation

Table 2 provides some examples of signal names recorded in the $10 \mathrm{~Hz}$ data files for a vehicle test.

Table 2: Example of signal names

Example signal names

Dyno_Spd[mph]

12VBatt_Volt_Hioki_U1[V]

Radiator_Air_Outlet_Temp[C]

Eng_spd_CAN2_rpm

Trans_oil_temp_TCU_C

\section{Explanation of the signal}

The speed of the rolls of the chassis dynamometer in miles per hour.

The voltage measurement of the $12 \mathrm{~V}$ accessory load battery from the Hioki power analyzer in Volts. Furthermore the channel on the power analyzer was 1.

The temperature of the air that crossed the main coolant radiator on the engine bay (air outlet of radiator) in degrees Celsius.

The speed signal of the engine in revolutions per minute (rpm). This is a vehicle signal collected with a direct tap on bus \#2 of the vehicle communication network.

The temperature of the transmission oil, as measured by the vehicle sensor in degrees Celsius. The signal is a diagnostic signal reported by the transmission control unit (TCU).

ANL-21/36: AMTL Vehicle Systems Instrumentation and Evaluation Methodology 


\subsubsection{Fuel flow measurements (PFI, DI, Coriolis, Modal, Bag)}

Fuel flow within the AMTL testing facilities may be measured in several different ways including: (1) Carbon balance fuel economy results from the emissions bench (bag and modal), (2) volumetric fuel flow measurement, or (3) mass fuel flow measurement. Each data stream provides unique benefits and levels of accuracy, dependent on specific testing and powertrain configurations. Due to this, the exact method of fuel flow instrumentation is vehicle dependent, and the vehicle specific report should be referenced for measurement points and routing. This report aims to provide a general baseline for understanding these measurements.

A first method for discussion is calculation of exhaust fuel flow based on a carbon balance of constituent emissions measurements from a dilute emissions analysis as described in the Code for Federal Regulations, Title 40, Part 600 [1]. An emissions bench (further detailed in section 2.2.5) can be used to calculate emissions with two separate methods, bag analysis or modal analysis. Emissions bag analysis is an analysis of dilute emissions collected over a specific duration of a test, known as a "phase" or "exhaust bag". As a totalized quantity of the emissions are analyzed, the result of the carbon balance of the constituents is the total mass of fuel used over that phase. Though this fuel use per emissions bag is calculated, the result is generally not used within reporting. Instead, the value is used to determine the overall vehicle fuel economy through standardized fuel economy calculations as per the Code for Federal Regulations [1]. For more details on fuel economy calculations from the emissions bench, please reference the relevant section of the Code for Federal Regulations, 40 CFR $600[1]$.

In addition to the fuel use calculation from bag, the AMTL calculates modal fuel flow from emissions constituents during testing. Modal results are captured by continuously sampling the exhaust emissions over the duration of a test. In much the same way bag emissions are calculated, modal emissions can determine the grams of fuel used at any one moment through a carbon balance. The resulting signal is a fuel flow signal in grams/second, reported from the emissions bench at $1 \mathrm{~Hz}$. When a modal fuel flow is available, it is labeled as AMA_Dilute_Fuel [g/s] or AMA_Dilute_Fuel_gps, depending upon the year the testing was completed.

Though the modal emissions method does provide a result of mass fuel flow, it does have notable shortcomings. As the calculations requires analysis of vehicle emissions, transient delays for the emissions to reach the analyzers can delay the response time (though a transient delay adjustment minimizes this impact). In addition, highly transient changes in emissions, such as from deceleration fuel cut off (DFCO), will be "smoothed" while the emissions transport through the exhaust system to the analyzers. Due to this, the AMTL staff instruments test vehicles for measuring fuel flow in two additional ways, one volumetric based and the other mass based, to capture fuel flow directly.

Volumetric fuel flow measurements are taken with Re-Sol RS840-060 fuel measurement systems, located in a vehicle specific location in the fuel line between the vehicle tank and the fuel rail. This device is suitable for all vehicles with return-less style fuel delivery systems. It is installed in-line with the vehicle fuel supply and makes use of a positive displacement flow meter to measure the volumetric flow rate of fuel consumed by the engine. The meter can measure flow rates between 0.3 and 60 liters per hour with an accuracy of $\pm 0.5 \%$ of the reading. When a volumetric fuel scale is used, it is labeled as Eng_Fuel_Flow_DirectX_ccps, where $X$ designates a DAQ input that is variable by vehicle. Note- a quick reference for this signal is the "Direct" designator, combined with the ccps (cubic centimeters per second) unit value.

ANL-21/36: AMTL Vehicle Systems Instrumentation and Evaluation Methodology 
In addition to volumetric fuel flow, mass fuel flow measurements may be captured. When instrumented, direct mass fuel flow is captured with a Micro Motion Coriolis flow meter of model \# CMF010M323NQBUEZZZ. This flow meter is installed in the same method as a volumetric fuel flow meter, where it is routed in line with the fuel supply from the vehicle tank. The meter has a nominal flow rate of $25.97 \mathrm{~g} / \mathrm{s}(93.5 \mathrm{~kg} / \mathrm{hr}$ ) with an accuracy of $\pm 0.1 \%$ of rate. When the Coriolis fuel flow meter is used, it is labeled as Eng_Fuel_Flow_DirectX_gps, where $X$ designates a DAQ input that is variable by vehicle. A quick reference for this signal is the "Direct" designator combined with the gps (grams per second) unit value.

An example of fuel flow configurations from a test vehicle can be seen in Figure 6. Additionally, both measurements systems, while in use for the system in Figure 6 are displayed in Figure 7. In this example, three direct fuel flow measurements were utilized to provide insight into fuel system operation on a vehicle with both direct and port fuel injection. A volumetric fuel flow meter measured flow to each fuel rail, while the mass fuel flow meter measured total fuel flow prior to distribution to the separate fuel rails.

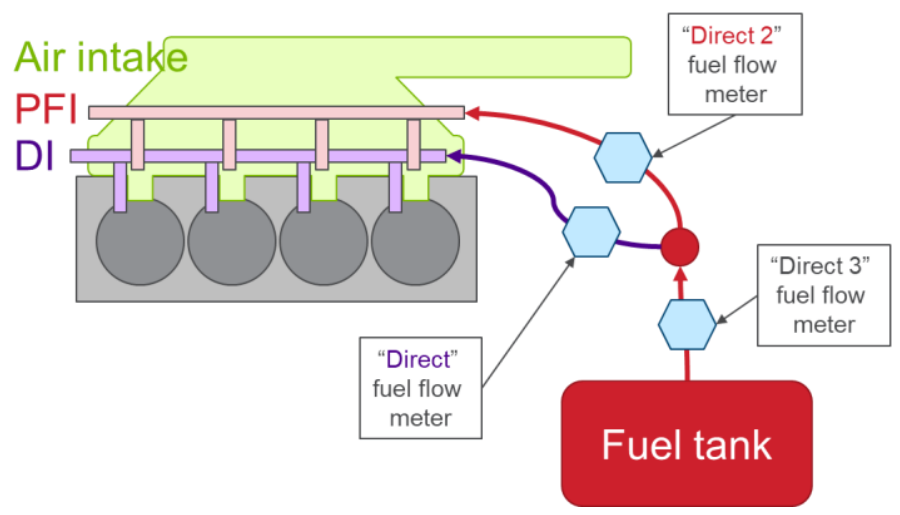

Figure 6: Instrumentation of Port and Direct Fuel Injection Systems on a 2018 Toyota Camry

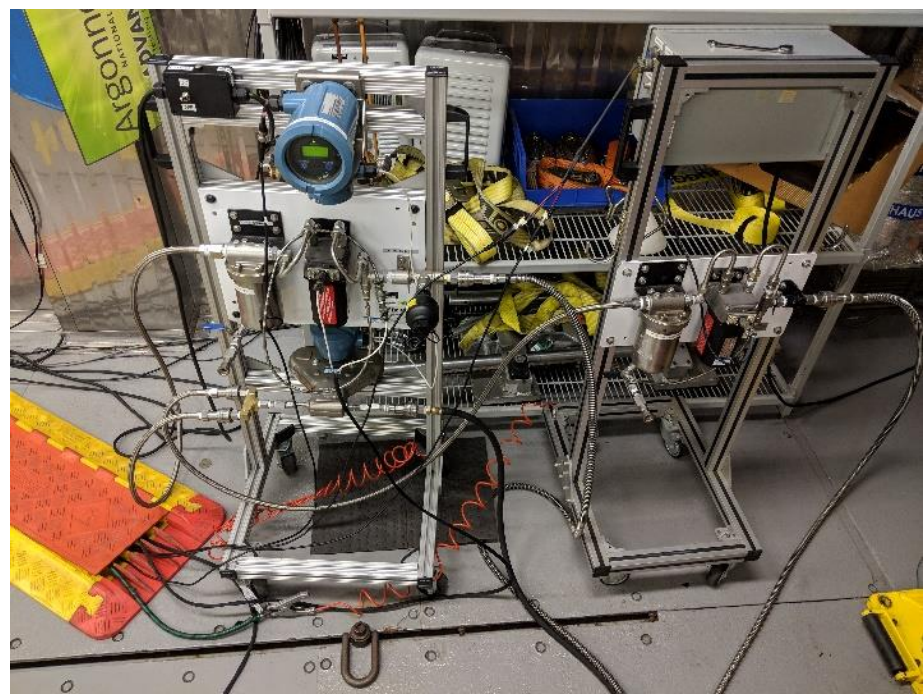

Figure 7: Direct Fuel Flow measurements via Fuel Scale and Coriolis flow meters

It should be noted that the addition of required hosing, though required for direct fuel flow analysis, results in some delay of the fuel flow signals due to expansion and contraction of the fuel

ANL-21/36: AMTL Vehicle Systems Instrumentation and Evaluation Methodology 
lines. Additionally, a small accumulator is used in series with the volumetric fuel flow meter to dampen the pressure pulses from high pressure fuel pumps on direct injection engines. Due to these differences, and the integration of measurement error from any continuous fuel flow measurement, cumulative values of fuel flow will vary between measurement devices over the extended duration of a drive cycle. Independent analysis should take this into account and use of the proper signal for the desired analysis conducted.

\subsubsection{Emissions}

\section{Fuel Economy from Emissions Bench Carbon Balance}

The 4WD test cell, contains a Peirburg AMA4000 dilute emission bench that measures the criteria emissions of total hydrocarbons (HCs), Non-methane hydrocarbons (NMHCs), oxides of nitrogen (NOx), and carbon monoxide (CO), as well as carbon dioxide $\left(\mathrm{CO}_{2}\right)$. These criteria emissions are captured whenever possible during testing, though they may be deactivated for specific tests such as high load passing or wide-open throttle maneuvers, or powertrain mapping tests. All signals captured from the emissions bench are labeled as "AMA_Dilute_" followed by the respective constituent emission.

Results from the emissions analyzers within this bench are used to calculate the fuel economy for both the modal emissions over the duration of the drive cycle, and the captured emissions bag at end

of test. The use of a carbon balance from an emissions bag to determine fuel economy is the standard method for determination of vehicle fuel economy as discussed within 40 CFR 600.112 [1]. Though other methods of fuel flow measurements are normally included within AMTL vehicle testing as mentioned in section 2.2.4, fuel economy results from emissions bag are used for comparison purposes in reporting, unless otherwise noted due to specific testing constraints.

An example of the use of an alternate signal to bag fuel economy would be fuel economy reporting during steady state speed tests. In this test, the vehicle is held at a steady state speed for a set period as described in section 4.4.1 of this report. As the emission bag method requires sampling constituent emissions of a bag sample over a set duration, considerable additional testing would be required to capture these with little additional value. Due to this, fuel economy is instead determined from either modal emissions or a method of direct fuel flow measurement.

\subsubsection{Electrical System Measurements- Low and High Voltage}

Advanced vehicle powertrains, conventional or electrified generally include instrumentation to capture power flow on low and high voltage system. Though the quantity, and location of these signal varies heavily based on vehicle architecture and accessibility, standardized instrumentation is used to capture these measurements.

Vehicle electrical systems measurements are captured with either a single, or multiple, Hioki 3390-10 power analyzers. Voltage and current measurements are captured from direct physical instrumentation, while power and energy use are calculated from the measured current and voltage channels within the power analyzer at a high frequency as described in the instrumentation documentation. The determination of the number of required channels, and the location of current measurements is vehicle dependent. Due to this, specific vehicle reports should be referenced to verify exact location and labeling of electrical system instrumentation.

ANL-21/36: AMTL Vehicle Systems Instrumentation and Evaluation Methodology 
Instrumentation for a power analyzer consists of a single current and voltage input per channel. Each direct measurement of current is completed with Hioki current probe. The model and range of each probe is determined after considering the expected measured current range, temperature conditions, and desired clamp precision. For most measurements, or in all temperatures which remain within the range of $-40^{\circ} \mathrm{C}$ to $+85^{\circ} \mathrm{C}$, Hioki CT6841(20A), CT6843(200A), CT6844(500A), or CT6846(1000A) current clamps are used, which provide a resolution of .3\% of the clamp amplitude. For locations where an ambient test temperature will remain within $0{ }^{\circ} \mathrm{C}$ to $40{ }^{\circ} \mathrm{C}$, Hioki CT9277 (20A), СT9278 (200A), or CT9279 (500A) may be used which provide a resolution of .5\% of the clamp amplitude.

Voltage for low voltage systems is generally measured across the $12 \mathrm{~V}$ battery. This input is then bridged to act as the source for all low voltage channels. On vehicles with medium or high voltage systems, a vehicle specific high voltage tap is invasively installed, which provides a voltage source to the corresponding high voltage channels. An additional voltage tap may be installed on plug in electrified vehicles (PHEVs) to capture voltage during vehicle charging. For instances where a high voltage tap is installed, the method and location of the tap will be documented in the vehicle report.

An example of vehicle electrical measurement instrumentation for both a conventional vehicle, and an electrified vehicle can be seen in Figure 8.

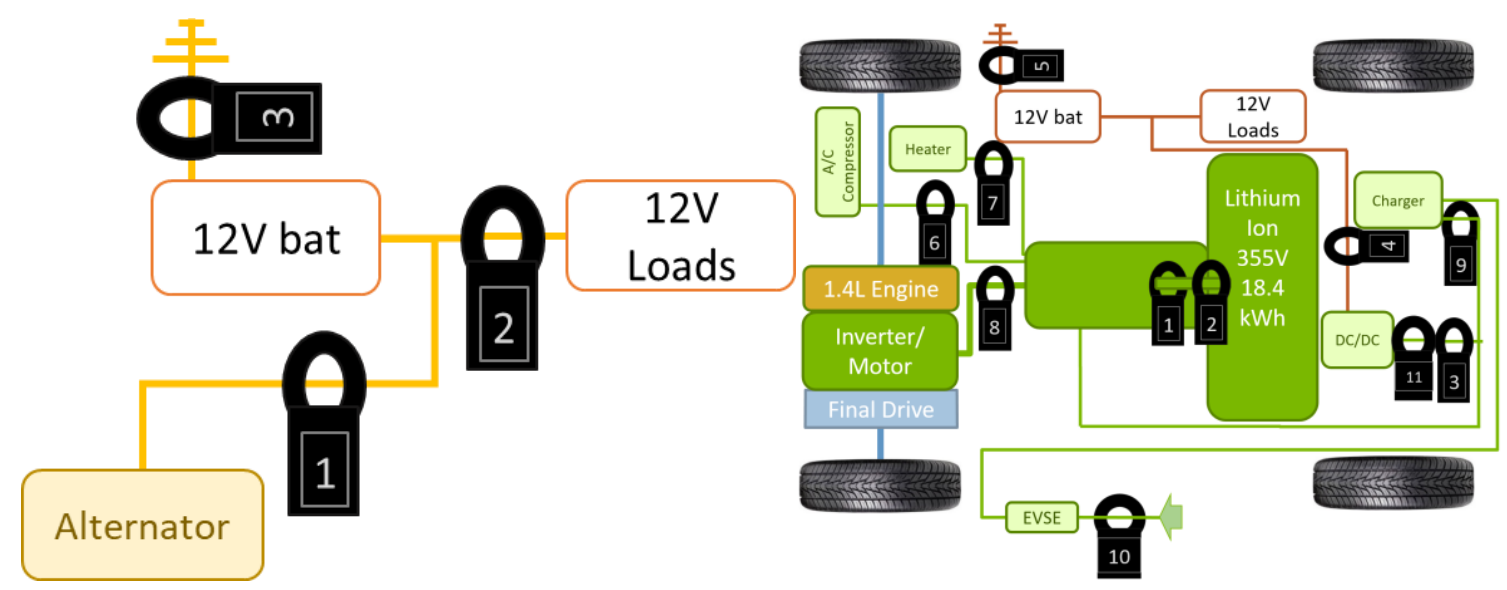

Figure 8: Overview of example electrical instrumentation on a conventional vehicle (left), and electrified vehicle (right)

Data collected from the power analyzers is logged in two ways; over analog DAQ inputs, and over an ethernet connection to the device. For analog measurement, specific signals are selected within the power analyzer and broadcast to analog inputs on the DAQ. The analog connection provides 1000 $\mathrm{hz}$ results of each selected signal, with the signals averaged, and collected at $10 \mathrm{hz}$ through the data acquisition system. These signals are labeled using the naming convention in Figure 5 , with the operational quantifier, set to the signal type and channel \#. The first letter corresponds to the signal type, which can be seen in the Table 3. The numeric value that follows is the measurement channel of the power analyzer.

ANL-21/36: AMTL Vehicle Systems Instrumentation and Evaluation Methodology 
Table 3: Designator list of Power Analyzer Measurements

\begin{tabular}{|l|l|l|}
\hline Designator & Measurement Type & $\begin{array}{c}\text { Units (unless } \\
\text { noted) }\end{array}$ \\
\hline $\mathbf{U}$ & Voltage & Volts \\
\hline $\mathbf{I}$ & Current & Amp \\
\hline $\mathbf{P}$ & Power & Watt \\
\hline IH & Integrated Current & Amp-hour \\
\hline WP & Energy & Watt-hour \\
\hline PWP & Positive Energy & Watt-hour \\
\hline MWP & Negative Energy & Watt-hour \\
\hline
\end{tabular}

The Ethernet connection provides a separate link to the power analyzer, where signals are processed through the power analyzer, rather than the DAQ. The signals from the Ethernet connection are reported at a lower rate, generally $1 \mathrm{hz}$, and the signal reported is an average of the signal listed. Though the sample rate is lower, the samples are processed at a higher rate within the power analyzer, resulting in higher accuracy for calculations such as integrated current $(\mathrm{IH})$ or energy (WP, PWP, MWP). Signals from this Ethernet connection are named only with the designator and channel number. A map of the location and number of each channel can be determined from referencing the vehicle specific electrical instrumentation overview (such as Figure 8) or referencing the signal designator from an analog input. An example would be an analog signal named Alternator_Curr_Hioki_I1, with a corresponding Ethernet signal simply labeled I1. Both signals would reference the current clamp (I) for channel 1 , as seen on the conventional vehicle seen in Figure 5.

\subsubsection{Analog Vehicle Instrumentation- Temperatures and Flows}

A standard, vehicle independent, form of instrumentation is the use of analog sensors such as thermocouples, flow sensors, and pressure sensors. Thermo-couples are typically installed to capture the engine oil, engine bay temperature, radiator outlet temperature, cabin vent outlet temperature, and ambient cabin temperature by the passenger head rest. Additional temperature measurements may be installed dependent upon powertrain technology and research goals, following the standard naming conventions established in section 2.2.2.

Instrumentation of flow sensors, such as in a coolant system, may additionally be included within a vehicle evaluation though are not standard. When installed, flow sensors instrumentation is chosen based upon estimated system flow rates. Once equipped, these sensors generally provide analog outputs then measured by the DAQ. If instrumented, the location of the flow sensors, and the specific sensors used will be discussed within the vehicle specific testing report. Additionally, the comprehensive list of analog instrumentation for each test vehicle is provided in the appendices of the specific test report for the car.

\subsubsection{Vehicular Communication Systems Instrumentation}

A core capability of the AMTL staff is the ability to decode vehicle internal communication messages (CAN). Over recent years, the AMTL staff have developed powerful tools and methods that enable the decoding of both broadcast and diagnostic CAN messages. These tools rely on an understanding of network wiring and messaging structure, the correlation between messages and ANL-21/36: AMTL Vehicle Systems Instrumentation and Evaluation Methodology 
known reference signals, the ability to mimic diagnostic message requests, and methods that can safely put the powertrain in specific planned scenarios to enable data collection for the decoding of certain signals.

For each test vehicle, the team decodes a significant number of signals from both broadcast and diagnostic vehicle communication. To access these signals, instrumentation generally includes the probing of multiple CAN networks across a vehicle, which are then routed to a single measurement location for data collection. An example of a measurement port can be seen in Figure 9. From this list of decoded signals, a subset of key signals is determined, based on a balance between message availability and sample rate. These final set of key signals is then captured over the duration of testing to provide specific insight into vehicle or components operation.

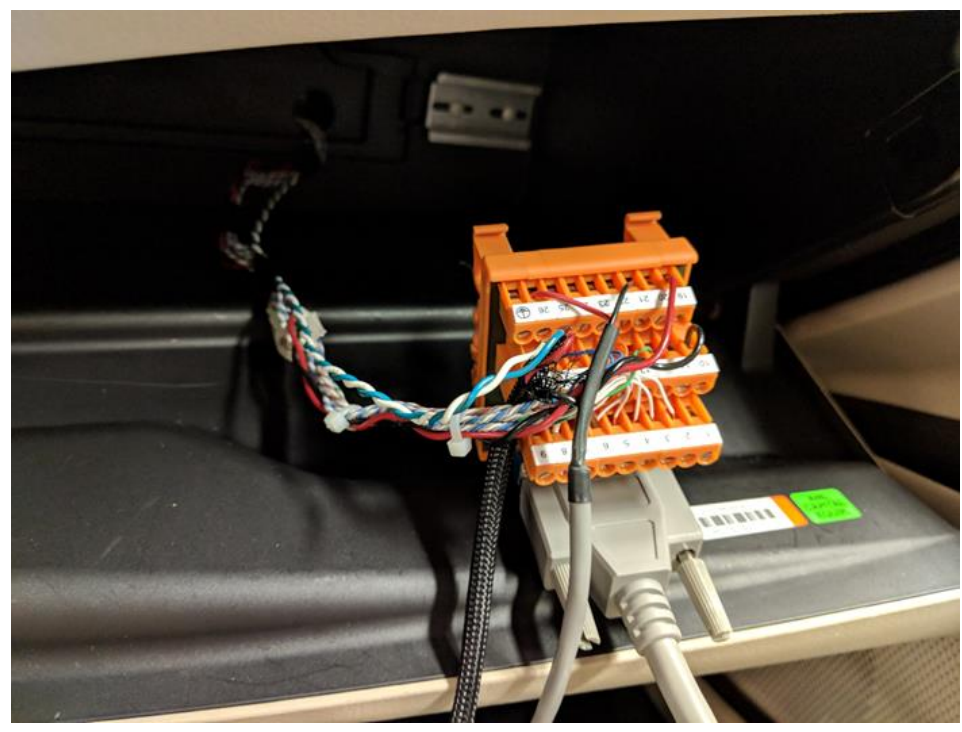

Figure 9: Example of a CAN Breakout point on a test vehicle

The corresponding communication and logging of signals is commonly completed through a combination of custom scripting within a combination of software and hardware communicating with the AMTL custom built DAQ. The specific communication messages that have been decoded may be found in the appendix of each vehicle report.

\subsection{Test Quality Control Process}

\subsubsection{Quality control program}

The quality assurance plan at Argonne's Advanced Mobility Technology Laboratory ensures the integrity and reliability of test data collected to meet the needs of varying research projects. The goal is to obtain data that are accurate, repeatable, and consistent with published or proprietary benchmark data. The plan describes the laboratory organization, the required qualifications for staff, the training procedures and requirements, the procurement procedures, the document control, the

ANL-21/36: AMTL Vehicle Systems Instrumentation and Evaluation Methodology 
records control, the experimental processes, the facility, and equipment maintenance, among other topics.

Further, the plan defines the calibration process, from the equipment list to the calibration schedule. The AMTL complies with Argonne's internal measurement and calibration protocol performed according to LMS-PROC-50, which addresses the general calibration requirements for M\&TE used in research and development(R\&D); Environment, Safety, Health and Quality (ESHQ) compliance monitoring and measurement; and Operations. At the facility, measuring and test equipment is maintained with certification traceable to NIST standards.

\subsubsection{Vehicle specific data quality check}

Initial vehicle setup focused on $Q C$

In contrast to other test facilities, Argonne often keeps a test vehicle mounted on the chassis dynamometer for an extended period of time- up to several weeks. For that reason, Argonne takes several days to setup the vehicle on the chassis dynamometer with a major focus on an in-depth quality check of all the sensors, signals, and instrumentation. All research essential signals in the data acquisition system are verified during this time, while additional signals may be logged for later review. The team performs full tests after which multiple staff member will analyze the data for correct trends, proper data ranges, and expected correlation of specific groups of signals. Where applicable, power and energy calculations are performed, and cross checked for expected results. Additionally, once initial testing has been performed, cycle-based fuel consumption results are compared to the results from other test laboratories such as those listed within the manufacturer certification documentation.

\section{Test by test $Q C$}

At end of each test, the data acquisition system automatically merges, post-processes the data for preliminary calculations, and produces several print outs and graphics for review. A standard printout provides a summary of the test including test, dyno, vehicle, fuel, and driver information over a strip chart of vehicle speed and target drive trace. Additionally, SAE J2951 [2] (see section 4.7) drive quality metrics on the printout are made available for review. The largest section of the summary printout provides a location for comparison of fuel economy results (carbon balance and direct measurements), electric energy consumption (or net change) and the emissions results for each phase of the drive cycle. For each test file, start comments from the dynamometer operator and the final comments (post-test) are recorded to allow for test specific notes. This master summary is reviewed after each test. In addition, the data acquisition system has several other paper or digital printouts the team will review including time resolved graphs of each signals, the environmental test cell conditions, and vehicle specific custom analysis graphs.

\section{Final data processing, analysis, and QC}

At the completion of vehicle testing, the team performs additional analysis of the extended data set to correct, document, or remove poor quality signals. Datasets of this magnitude require continually evolving data management procedures to maximize the number of signals available for analysis. Following this review, the data is processed and shared with other groups such as Argonne's Vehicle Systems Modeling team who perform additional review. Following this internal review 
process, subsets of testing data may be posted publicly on Argonne's Downloadable Dynamometer Database [4].

\section{Research acquisition, preparation, and instrumentation}

\subsection{Vehicle Selection and Acquisition}

The first step to a vehicle technology assessment program is proper selection of testing vehicles. Vehicles are selected as a collaborative effort between the project sponsor and Argonne's experimental and simulation focused research staff. Vehicles are selected to provide insight into advanced powertrain technologies and validate and enhance the accuracy of modeling and simulation efforts. Following determination of a specific vehicle powertrain, model specific options and packages are reviewed and selected to provide additional research insight and improve test to test repeatability.

An example of a system that provides additional research insight is automatic climate control. As testing is performed at ambient temperatures above and below $72^{\circ} \mathrm{F}$, automatic climate control has a direct impact on vehicle energy consumption. At above ambient (hot) temperatures, the air conditioning system provides a load on the powertrain, and the system provides control of cabin temperature, airflow, and $\mathrm{AC}$ compressor operation. At low temperatures, the climate control system impacts the thermal state of the vehicle powertrain, as coolant flow to the passenger cabin impacts waste heat available for the powertrain.

Following full specification of a desired research vehicle, the specific vehicle is then acquired through a procurement process as directed by practices established by the Argonne Procurement Department that comply with the US Department of Energy Prime Contact.

\subsection{Vehicle Preparation Prior to Testing}

Prior to testing, a new vehicle must be conditioned, or "broken in", to ensure consistent vehicle state losses of tires, moving and rotating components, and to ensure catalyst "degreening". A standard of 4,000 miles is established for proper vehicle break-in of internal combustion engine vehicles, while 2,000 miles is standard for electrified only vehicles, as is described in the Code for Federal Regulations [1][2]. These preliminary miles can be completed either on road, on a chassis dynamometer, or a combination of both. The chosen method of break-in depends upon the several factors including vehicle architecture, external testing requirements, facility availability, and allocated budget. On-road mileage accumulation of at least 2,000 miles is desired to ensure proper break-in of vehicle tires and other rotating components, which may not be exercised on a 2WD chassis dynamometer. Additionally, for most test vehicles, some preliminary vehicle instrumentation is completed prior to break-in. During on-road mileage accumulation, this instrumentation can then be leveraged to provide data for preliminary review, validation, and analysis.

ANL-21/36: AMTL Vehicle Systems Instrumentation and Evaluation Methodology 
A key component of an effective break-in is variations in powertrain speed and loading. Break-in miles accumulated on-road inherently provide this variability, but operation on a chassis dynamometer is dependent on the driving cycle completed. To ensure variability while accumulating miles on dynamometer, several custom drive cycles have been created from collected on-road data with varying acceleration rates and speeds. An example of a developed drive trace can be seen in Figure 10 below.

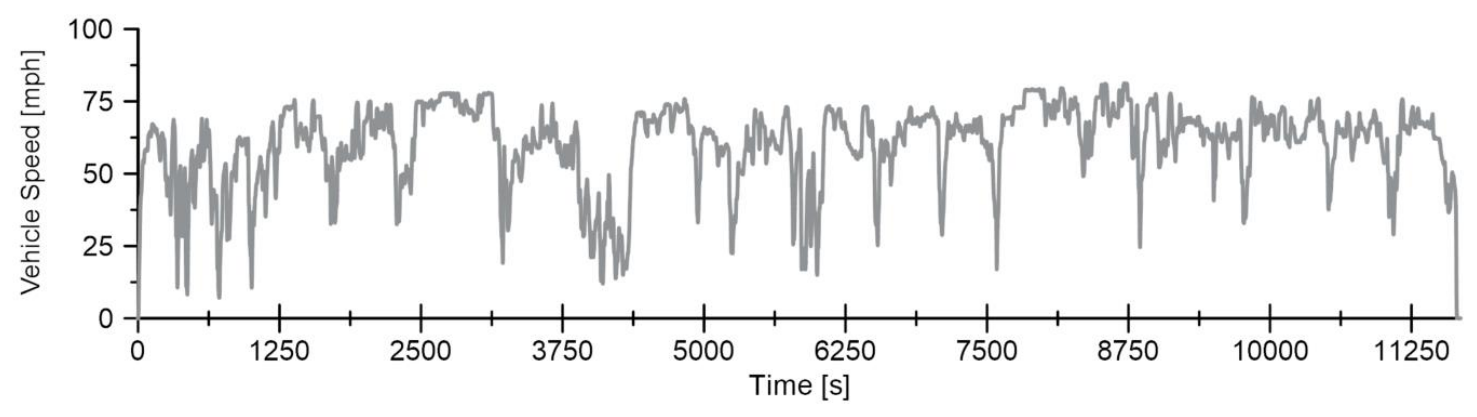

Figure 10: Drive cycle developed from on-road data for on dyno mileage accumulation

A custom-built robot driver generally provides vehicle operation during the on-dynamometer mileage accumulation. Further details of this robotic driver can be found in section 4.6 of this report. The use of the robotic driver allows for consistent mileage accumulation while reducing project burden. A test vehicle during mileage accumulation can be seen on the AMTL 2WD chassis dynamometer Figure 11. 


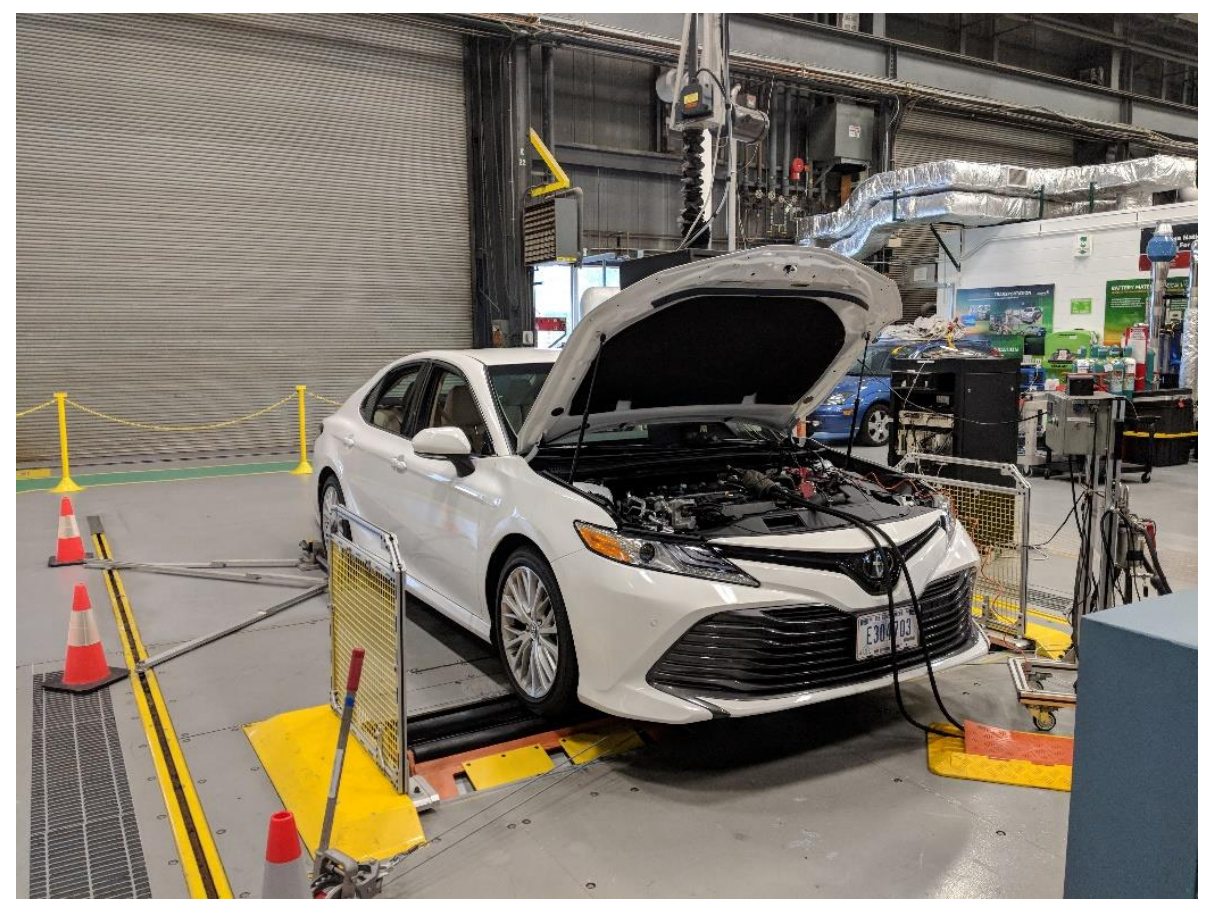

Figure 11: Vehicle mounted for mileage accumulation on the AMTL 2WD chassis dynamometer.

\section{Testing Overview}

\subsection{Argonne's approach to vehicle testing and differences to certification testing}

\subsubsection{Research philosophy drives testing efforts}

The major focus of certification testing is to provide robust, repeatable vehicle evaluations to ensure fuel economy and emission compliance within the regulatory framework. The testing that Argonne performs differs from standard certification testing in two specific dimensions: (1) the depth of instrumentation; and (2) the breadth of test types and testing conditions. While standard certification testing performed by the EPA focuses on certification drive cycles fuel economy and tailpipe emissions on a very large number of cars, Argonne targets a much smaller set of vehicles (and therefore of powertrains) with the intent to characterize the components in each powertrain across a wide range of conditions.

Like certification testing, Argonne measures fuel consumption and tailpipe emissions at the vehicle level for specific drive cycles. Argonne testing provides additional value with in-depth information on specific powertrain components and characterization of component operational areas, efficiencies, and performance limits (where possible). This comprehensive instrumentation approach allows the research staff to determine overall powertrain behavior, and how each component contributes to the powertrain system efficiency on both standard and non-standard drive cycles.

In addition to standard certification drive cycles (as described in section 4.3), testing covers many other transient drive cycles, performance tests, and component mapping tests across a range of

ANL-21/36: AMTL Vehicle Systems Instrumentation and Evaluation Methodology 
ambient temperatures. The performance testing typically includes maximum accelerations, passing maneuvers, and grade testing (as described in section 4.4). Additionally, component mapping often includes steady state speed testing with a focus on specific component operation areas.

\subsubsection{Argonne's test cell and vehicle setup}

The Argonne testing deviates from certification testing as Argonne's goal is research fidelity rather than regulatory compliance. Based on this intent, the staff may purposefully choose to change specific aspects of the test procedures to document vehicle operation in real world conditions. The next paragraphs describe some of the variations in vehicle testing which are unique to testing at the AMTL.

- Speed-matched fan: In order to provide results close to real world conditions, Argonne often uses a fan in front of the vehicle set to a 'speed match' mode and has the vehicle hood closed for all testing at any ambient temperature. This deviates from certification testing requirements described in the Codes of Federal Regulations [1], which requires the vehicle hood to be open and the fan to operate at a constant speed of 5,300 scfm for the standard UDDS and HWFET drive cycles unless otherwise approved by the administrator. Argonne has determined that there is a small, but measurable different in fuel consumption between these two vehicle configuration at $72^{\circ} \mathrm{F}$ and especially at $20^{\circ} \mathrm{F}$ and $95^{\circ} \mathrm{F}$. Additionally, certification style tests are performed on each test vehicle to provide a direct comparison of the testing methods.

- Emission bench set-up: The second test setup difference is that Argonne continuously runs a diluted exhaust sample through the emissions analyzers during the drive cycle testing to obtain modal (time resolved) emission data. Therefore, the emission bags are not sampled immediately after the end of a test phase, but instead sampled immediately at the end of a full test. Argonne has run some experiments to compare both procedures and found statistically insignificant differences in fuel consumption results. Due to this result, the staff have chosen to sample to emissions bags at the end of the test to obtain the time resolved modal emission data, which is used for all vehicle testing.

Figure 12 details the vehicle and equipment setup used by Argonne for chassis dynamometer testing. The vehicle cooling setup and the emissions bench sampling are the two major differences seen over the duration of vehicle testing, though additional certification style (hood up/ constant speed fan) comparison tests may be performed for each test vehicle. The $20^{\circ} \mathrm{F}$ testing at Argonne is performed on the same certification fuel as the $72^{\circ} \mathrm{F}$ and $95^{\circ} \mathrm{F}$ tests. Furthermore, the target road load coefficients are not readjusted for $20^{\circ} \mathrm{F}$ testing as they are for certification testing. 


\begin{tabular}{|c|c|c|c|}
\hline & $\begin{array}{l}20^{\circ} \mathrm{F} \text { ambient } \\
\text { temperature }\end{array}$ & $\begin{array}{l}72^{\circ} \mathrm{F} \text { ambient } \\
\text { temperature }\end{array}$ & $\begin{array}{l}95^{\circ} \mathrm{F} \text { ambient } \\
\text { temperature }\end{array}$ \\
\hline Origin & - Cold CO and HC test & $\begin{array}{l}\text { - UDDS, HWFET and } \\
\text { US06 }\end{array}$ & $\begin{array}{l}\text { - SC03 test with air } \\
\text { conditioning }\end{array}$ \\
\hline Road load & \multicolumn{3}{|c|}{$\begin{array}{l}\text { - Listed EPA listed coefficients, unless otherwise provided } \\
\text { - Target coefficients used are listed in the summary sheet for each vehicle }\end{array}$} \\
\hline Cooling fan & $\begin{array}{l}\text { - Vehicle Speed match } \\
\text { mode }\end{array}$ & $\begin{array}{l}\text { - Vehicle Speed match } \\
\text { mode }\end{array}$ & $\begin{array}{l}\text { - Vehicle Speed match } \\
\text { mode }\end{array}$ \\
\hline Hood position & - Hood down & - Hood down & - Hood down \\
\hline $\begin{array}{l}\text { Window } \\
\text { position }\end{array}$ & - Windows closed & - Windows open & - Windows closed \\
\hline Climate control & $\begin{array}{l}\text { - Automatic mode } \\
\text { - } 72^{\circ} \mathrm{F} \text { target temp }\end{array}$ & - OFF & $\begin{array}{l}\text { - Automatic mode } \\
\text {. } 72^{\circ} \mathrm{F} \text { target temp }\end{array}$ \\
\hline Solar lamps & - OFF & - OFF & $\begin{array}{l}850 \mathrm{~W} / \mathrm{m}^{2} \text { radiant } \\
\text { solar energy }\end{array}$ \\
\hline \multirow[t]{2}{*}{$\begin{array}{l}\text { Additional } \\
\text { notes }\end{array}$} & $\begin{array}{l}\text { - Target road load not } \\
\text { necessarily readjusted } \\
\text { - Cold temperature fuel } \\
\text { not used for AVTE }\end{array}$ & - None & - None \\
\hline & \multicolumn{3}{|c|}{$\begin{array}{l}\text { Valid at all temperatures } \\
\text { - Modal and bag measurements simultaneously }\end{array}$} \\
\hline
\end{tabular}

Figure 12: Vehicle test setup at Argonne

Typically, the vehicle test setup described in Figure 12 applies to testing performed at the AMTL. When the testing used a setup varies from this standard, the variations for specific test are described in the vehicle specific testing reports.

\subsection{Vehicle Chassis Dynamometer Setup and Loss Determinations}

Argonne uses the test weight and road load coefficients published by vehicle manufacturers through the EPA test car database [5] and manufacturer provided certification documentation [6] for all test vehicles unless otherwise noted. Following preliminary vehicle instrumentation, the vehicle is mounted on the chassis dynamometer. Following vehicle operational review and preliminary signal checks, the vehicle is driven on a preparation HWFET drive cycles as required by SAE J1263 "Road Load Measurement and Dynamometer Simulation Using Coastdown Techniques" [7] immediately after which, the vehicle loss determination procedure is performed using the chassis dynamometer interface. Following review, the derived vehicle dyno set coefficients are accepted, saved, and applied to the road load emulation. This procedure is repeated several times over the course of vehicle testing to determine if vehicle losses have changed while the vehicle is on the chassis dynamometer.

Vehicle testing may be in 4WD mode using both the front and the rear rolls of the chassis dynamometer, or in 2WD mode where only the driven axle spins. This setup decision depends on the vehicle behavior in 2 WD mode, and if the team can engage a chassis dynamometer mode that supports 2WD mode testing. In 4WD test mode the vehicle is restrained on the chassis dynamometer using chains linked to towers at each corner of the vehicle. In 2WD mode the non-driven axle will be clamped to a track system in the test cell. In both cases a vehicle alignment routine is performed 
before the vehicle loss is determined as per SAE J2951 [3]. Typically, vehicle setup occurs only once over the duration of vehicle testing, and the vehicle remains in the specific test mode following setup.

In instances where vehicle setup changes, the change will be noted in the vehicle specific testing report. Additionally, the vehicle specific report provides the target road load coefficients used as well as the dyno set coefficients that resulted from the vehicle loss determination.

\subsection{Standard Drive Cycle Testing Overview}

The typical daily test sequence consists of the Urban Dynamometer Drive cycle (UDDS), Highway drive cycle (HWFET), and the USO6 drive cycles at the $72^{\circ} \mathrm{F}$ ambient temperature, and the AMTL process for performing certification testing follows the Code for Federal Regulations [1][2], unless otherwise noted. The following section will provide an overview of the specific testing process used in testing at the Argonne.

The AMTL test sequence for certification testing of a internal combustion vehicle includes a cold start UDDS, a hot start UDDS, a third UDDS, followed by a pair of HWFET, then pair of US06 cycles. The preparation for the cold start test consists of completing a UDDS cycle at $72^{\circ} \mathrm{F}$ and leaving the vehicle to thermally soak at $72^{\circ} \mathrm{F}$ for over 12 hours. The overnight soak is conducted on the chassis dynamometer in the test cell as the vehicle remains mounted on the rolls for the duration of the testing.

The graph in Figure 13 shows the sequence of drive cycles executed for the vehicle testing. Note that a 10-minute soak period is held between the UDDS cycles as noted in the figure. The test sequence is repeated at least three times over the course of subsequent days. In Figure 13, the fuel economy numbers in the reports are based on the test phases highlighted by the pink boxes. The phases for the USO6 drive cycle are the split city and HWFET phases needed to calculate the EPA 5cycle fuel economy label.

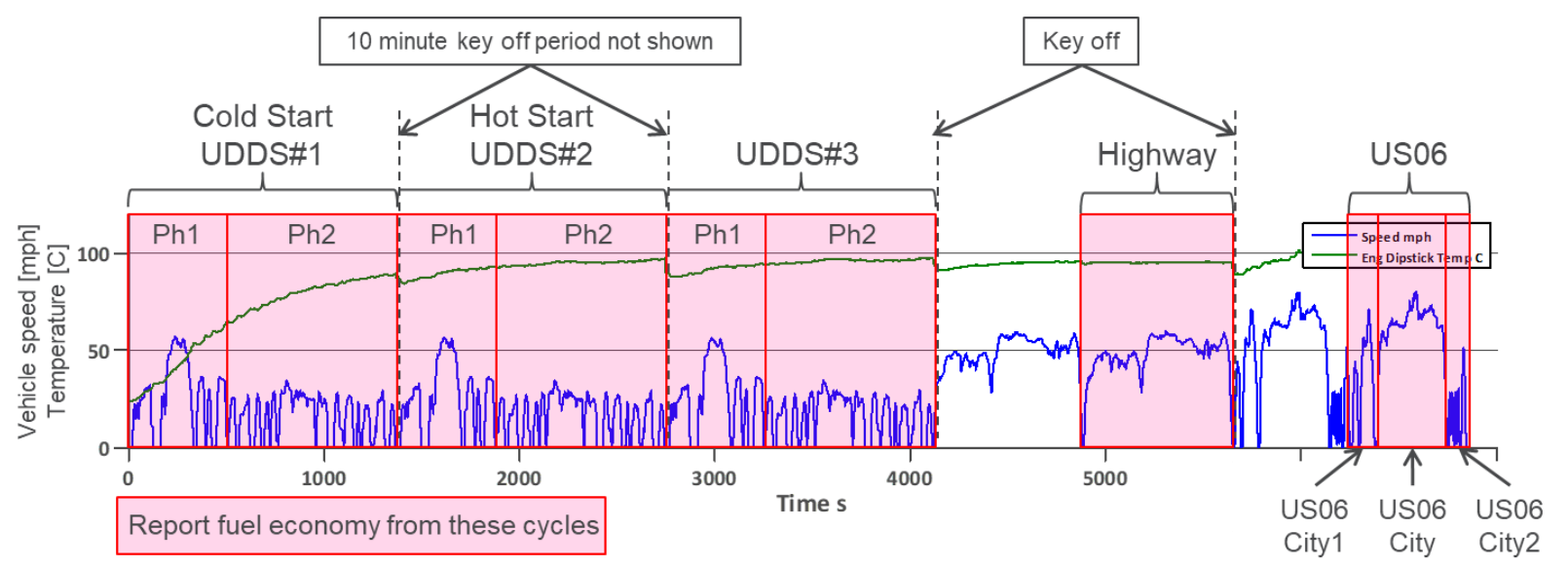

Figure 13: Daily drive cycle test sequence executed in the morning 
In general, the certification cycle test sequence in Figure 13 is repeated three times to establish statistical confidence in the fuel economy results. This same test sequence is usually repeated once at $20^{\circ} \mathrm{F}$ and $95^{\circ} \mathrm{F}$ with $850 \mathrm{~W} / \mathrm{m}^{2}$ of solar load. In the case of testing of varying fuels, the same test sequence would be used for the comparison, in addition to fuel specific testing. Table 4 shows the typical drive cycles that are executed for a vehicle technology assessment at Argonne. Note that additional drive cycles are typically added and listed within the final vehicle specific test plan.

Table 4: Typical test plan for vehicle technology assessments

\begin{tabular}{|c|c|c|c|c|}
\hline Test cycle / Test conditions & $72^{\circ} \mathrm{F}$ & $\begin{array}{c}95^{\circ} \mathrm{F}+ \\
850 \mathrm{~W} / \mathrm{m}^{2}\end{array}$ & $20^{\circ} \mathrm{F}$ & $\begin{array}{l}72^{\circ} \mathrm{F} \text { Tier } 3 \\
\text { fuel }\end{array}$ \\
\hline UDDSx3 (including cold start) & $3 x$ & UDDS $x 2$ & $x$ & $3 x$ \\
\hline$H W Y \times 2$ & $3 x$ & $2 x$ & HWYX3 & $3 x$ \\
\hline US06×2 (4bag) & $3 x$ & $2 x$ & $x$ & $3 x$ \\
\hline $5 C 03 \times 2$ & N/A & $2 x$ & $\mathrm{~N} / \mathrm{A}$ & N/A \\
\hline $\begin{array}{l}\text { Steady state speed testing @ } \\
0 \%, 3 \% 6 \% \text { grade }\end{array}$ & $\mathrm{X}$ & $x$ & & $\mathrm{X}$ \\
\hline $\begin{array}{l}\text { Passing maneuver testing @ } \\
0 \%, 3 \%, 6 \% \text { grade }\end{array}$ & $x$ & & & $\mathrm{x}$ \\
\hline Maximum acceleration $x 3$ & $x$ & & & $\mathrm{x}$ \\
\hline
\end{tabular}

Table 4 also includes some specialized testing, such as steady state speed, passing maneuver and maximum acceleration tests, that facilitate powertrain component model development and validation. These tests are described in more details in the next section.

\subsection{Specialized Testing Overview}

Determination of component and controls operation and limitations is often best characterized by focused testing in which vehicle operation can be controlled. This section will provide an overview of the specialized methods and testing developed and used within the research program at the AMTL.

\subsubsection{Steady State Speeds}

Steady-state speed tests determine vehicle operation while the vehicle is driven at a constant speed and load point. These cycles are conducted by following a constructed driving schedule and are completed with a minimum 30 seconds at each speed and are held until stability is determined. Vehicle speed is increased in $10 \mathrm{mph}$ increments up to $80 \mathrm{mph}$, held for the set duration, and then decreased to a stop in $10 \mathrm{mph}$ increments. Holding each speed following both increasing and decreasing speed captures variability in powertrain operation and vehicle thermal state. This cycle is often repeated at a series of varying grades to capture impacts in vehicle loading while traveling at a steady state speed.

ANL-21/36: AMTL Vehicle Systems Instrumentation and Evaluation Methodology 
Prior to each steady state speed cycle, the vehicle is warmed to an engine oil temperature of over $80^{\circ} \mathrm{C}$, or similar to that seen as on a transient drive cycle. This is often conducted by operating at a state speed prior to beginning the test. An overview of a single phase 'stairs' of this drive cycle can be seen in Figure 14.

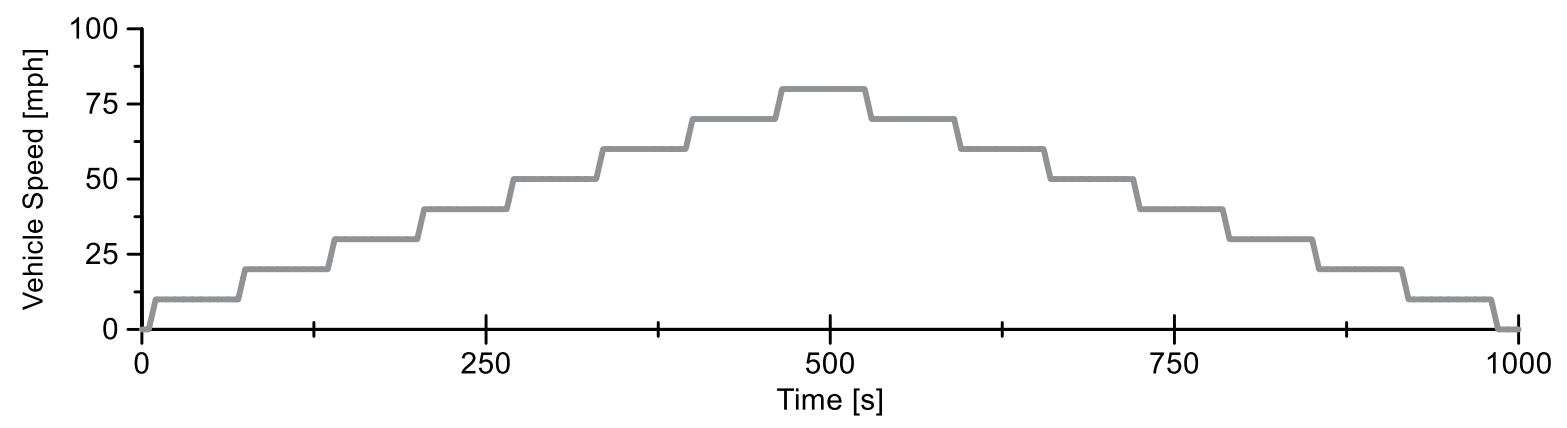

Figure 14: Overview of single phase of the steady state drive cycle

\subsubsection{Powertrain Mapping Cycles}

Limitations and operation of the vehicle powertrain are not commonly seen during operation on transient drive cycles. To properly map powertrain operation, custom cycles are used to control vehicle operation and effectively map component operation. To map powertrain operation, a combination of custom drive cycles, a robotic driver, and feedback from focused instrumentation is used. Three varying methods for powertrain mapping are commonly used, and an overview provided in the following pages.

A first method consists of the dynamometer being placed in road load simulation mode, and accelerating with fixed accelerator pedal inputs (blue), as can be seen Figure 15.

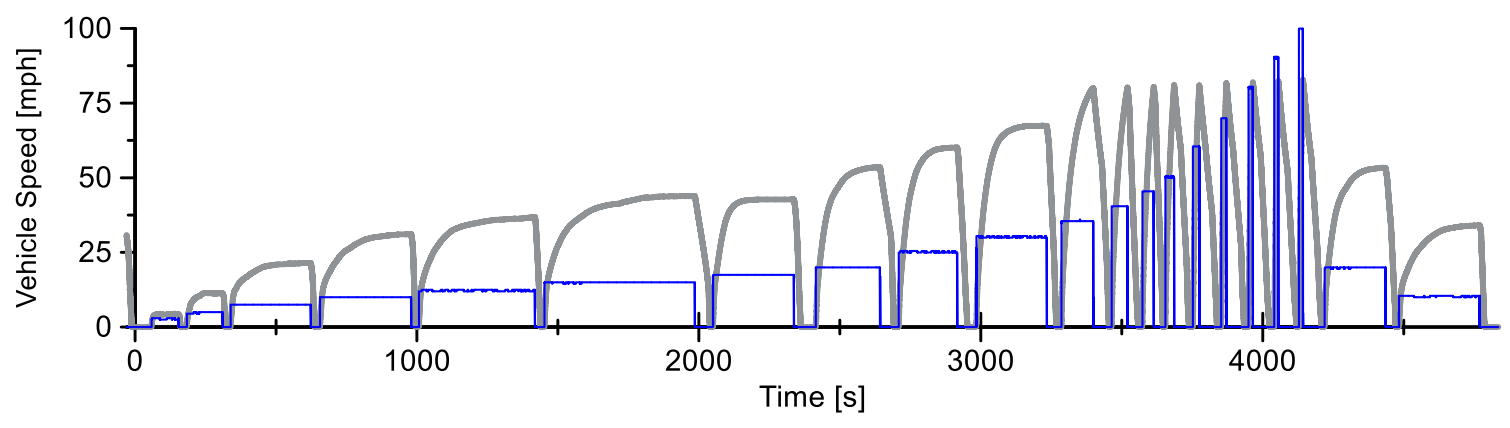

Figure 15: Vehicle Acceleration with varying constant pedal inputs

ANL-21/36: AMTL Vehicle Systems Instrumentation and Evaluation Methodology 
This method provides a map of load demand and upshift strategy for the full range of powertrain operation. Accelerator pedal inputs are generally varied in smaller increments at lower pedal positions and varied in larger increments as accelerator pedal position increases.

To characterize downshifting of a vehicle transmission, a different testing strategy is required. An overview of the cycle can be seen in Figure 16. Testing was conducted with the dynamometer placed into a mode that provides ramps of constant acceleration and deceleration rate of $2 \mathrm{mph} / \mathrm{s}$. This speed was chosen as a tradeoff between a low acceleration rate which provides focused shift points, but high enough to avoid component overheating. During ramp cycles, the accelerator pedal input (in blue) was held constant while vehicle speed varied.

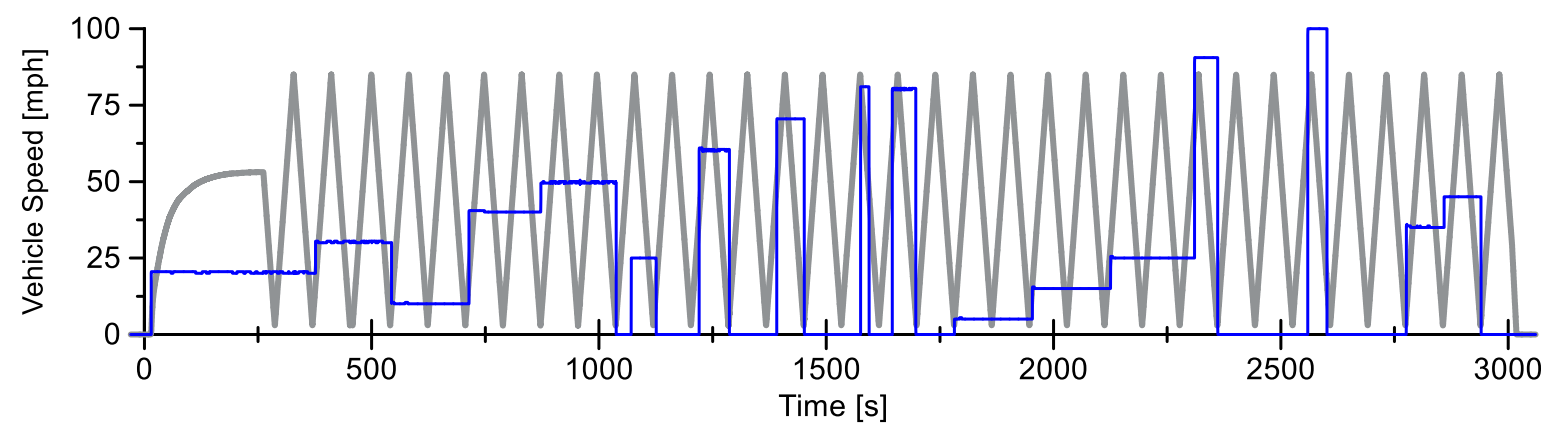

Figure 16: Constant acceleration ramp cycles with varying accelerator pedal inputs

One additional method of powertrain mapping focuses on engine mapping, in which the goal is to develop a map of varying engine speed vs load. Engine mapping of a vehicle on a chassis dynamometer is inherently challenging when compared to an engine dynamometer due to transmission operation, which can lead to "holes" in the map caused by the torque converter operation, or transmission shift commands. To avoid these "holes "the AMTL staff may attempt to implement control overrides to demand transmission gear and force the torque converter into lockup, and / or lock the transmission into a specific gear. Once successful, the chassis dynamometer may be locked into a set speed, and the vehicle accelerator pedal position varied to map engine torque and speed points. The success of this method is dependent on the test vehicle, and duration of time available for development.

\subsection{3. $25 \%$ grade test- maximum vehicle acceleration}

To capture vehicle operation under a high load, the AMTL will conduct a test with the dynamometer set to represent vehicle operation on a $25 \%$ grade. At this grade, the vehicle will be accelerated to either a maximum attainable vehicle speed, or a maximum speed of $80 \mathrm{mph}$. If a vehicle is not capable of reaching this max speed, the end of test is determined as when vehicle speed stabilizes or shifts to a negative value.

\subsubsection{Idle fuel flow testing}

Idle fuel flow tests are conducted to capture the vehicle powertrain warm up, and idle fuel flow rates while the vehicle is at a rest. Idle fuel flow tests are conducted with the vehicle started from a 
cold start following preconditioning at temperature for 12 hours prior. The vehicle is started and remains at idle until either a set duration of time has elapsed, generally $30 \mathrm{mins}$, or the powertrain is found to reach thermal stability.

\subsection{Test Fuel Selection}

One important factor in the fuel economy determination found during chassis dynamometer testing is the test fuel which is used. Test fuel selection involves several variables, including energy content, octane, heating value, and others. For standard vehicle technology, Argonne uses standard certification fuel such as Tier 2 or Tier 3 fuel. The fuel selection is made based on research requirements, the vehicle fuel recommendation, and the fuel used in reported fuel economy certification testing.

In several vehicle technology assessments, two fuels were used to evaluate the impact of high versus low octane on the engine operation and vehicle efficiency. Table 5 and Table 6 provide example fuel specifications for Tier 3 and Tier 2 fuel used in prior vehicle testing. For specifications of the exact test fuels used during vehicle testing, please reference the vehicle specific report.

Table 5: Main specifications of an example EPA Tier 3 EEE fuel

\begin{tabular}{|l|l|}
\hline Fuel Name: & HF2021 EEE Tier 3 \\
\hline Ethanol Content & $10 \%$ \\
\hline Carbon weigh fraction & 0.827 \\
\hline Density & $0.744[\mathrm{~g} / \mathrm{ml}]$ \\
\hline Net heating value & $17958[\mathrm{BTU} / \mathrm{lbm}]$ \\
\hline Research Octane Number & 91.9 \\
\hline Motor Octane Number & 83.3 \\
\hline R+M/2 & 87.6 \\
\hline Sensitivity & 8.6 \\
\hline
\end{tabular}

Table 6: Main specifications of an example EPA Tier 2 EEE fuel

\begin{tabular}{|l|l|}
\hline Fuel Name: & HF0437 EEE Tier 2 \\
\hline Ethanol Content & $0 \%$ \\
\hline Carbon weight fraction & 0.8658 \\
\hline Density & $0.743[\mathrm{~g} / \mathrm{ml}]$ \\
\hline Net heating value & $18627[\mathrm{BTU} / \mathrm{lbm}]$ \\
\hline Research Octane Number & 96.8 \\
\hline Motor Octane Number & 89.1 \\
\hline R+M/2 & 93.0 \\
\hline Sensitivity & 7.7 \\
\hline
\end{tabular}

\subsection{Driver selection}

Argonne has experienced dynamometer drivers who have driven test cycles on chassis rolls for decades. These professional drivers are used for most of the vehicle testing. Typically, the vehicle is

ANL-21/36: AMTL Vehicle Systems Instrumentation and Evaluation Methodology 
operated by human driver on all the drive cycle-based tests. The driver's goal is to match the vehicle speed to the drive cycle displayed on the drivers aid screen with a great attention paid to even the smallest changes in the drive trace.

In addition to trained drivers, Argonne has developed a robot driver which is often used specialized tests such as mapping or steady state speeds (as described in section 4.4). These focused tests yield the best data when step change inputs on braking or accelerator inputs can be executed precisely and repeatable, and subsequently held constant- an operation more easily performed by an actuator than human driver.

Both the robot hardware and control software were developed in house at Argonne and have been refined through testing over the course of several years. This robot driver, which is shown in Figure 17, is composed of two oversized linear actuators. The first actuator operates the accelerator pedal and the second actuates the brake pedal. The control software is implemented directly in the AMTL custom data acquisition system to provide benefits to control from inputs from the vehicle and testing environment. Several software features - such as look ahead, gain scheduling, and active feedforward learning - enable the staff to fine tune the robot driver to the powertrain and certification cycles.

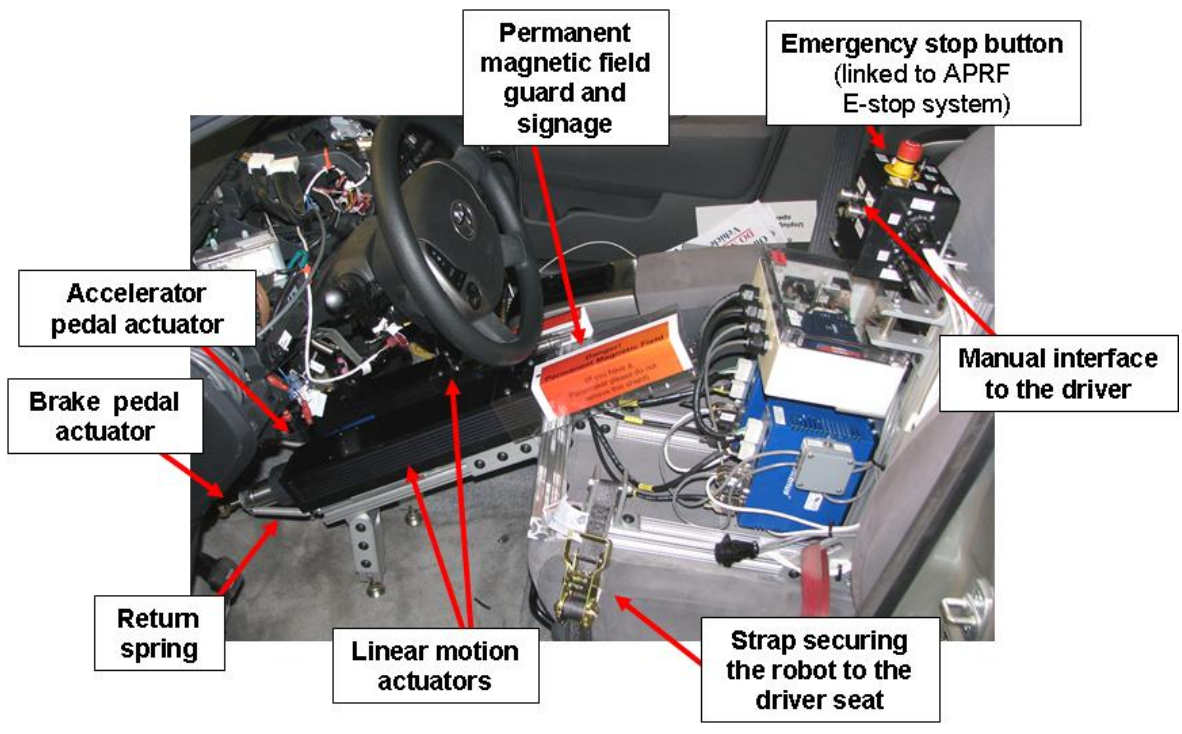

Figure 17: Argonne custom robot driver installed in a vehicle

Each specific vehicle report has an appendix that contains a summary of the vehicle tests performed for the technology assessment. Within this table, driver selection (Robot or human) is noted for each specific test. 


\subsection{SAE J2951 Drive Quality Metrics}

The SAE J2951 ${ }^{\mathrm{TM}}$ "Drive Quality Evaluation for Chassis Dynamometer Testing" [3] defines a set of parameters aimed at quantifying how close the driving speed trace followed the actual drive trace. The procedure clearly prescribes the different data processing and calculation steps to generate these parameters. Argonne staff members were actively involved in developing the drive quality metrics through mathematical concepts as well as performing the target chassis dynamometer testing.

The J2951 metrics are the Energy rating (ER), the Distance Rating (DR), the Energy Economy Rating (EER), Absolute Speed Change Rating (ASR) and the Root Mean Squared Speed Error (RMS). The standard clearly defines how to process the $10 \mathrm{~Hz}$ data from the drive schedule and the measured driven speed along with the vehicle characteristics (test weight and road load) to calculate the positive driven cycle energy (CEd) which is the foundation is the J2951 energy and economy ratings. The CEd can also be used for powertrain efficiency calculations. The energy rating is the percent difference between the positive driven cycle energy to the positive drive cycle energy. The distance rating is the percent difference between the total driven distance and the drive cycle distance. The energy economy rating combines the ER and DR into an economy rating. The absolute speed change rating compares the acceleration and deceleration rates between the driven trace and the drive trace. The RMS error provides the mathematical root mean square error between the driven trace and the drive trace. Figure 18 shows a few of the drive quality metrics that resulted from a past study focused on the how these parameters change with different drivers.

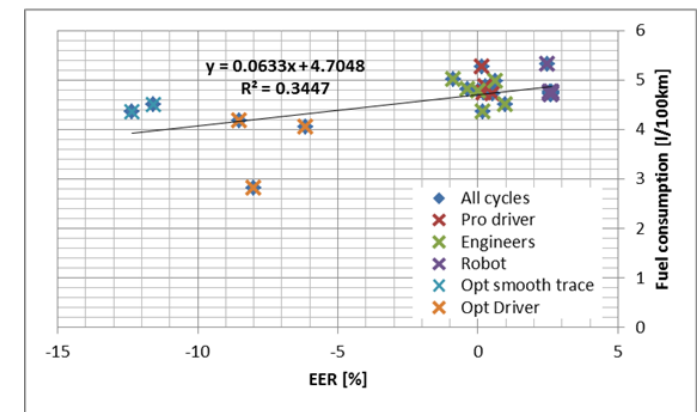

Energy Economy Rating

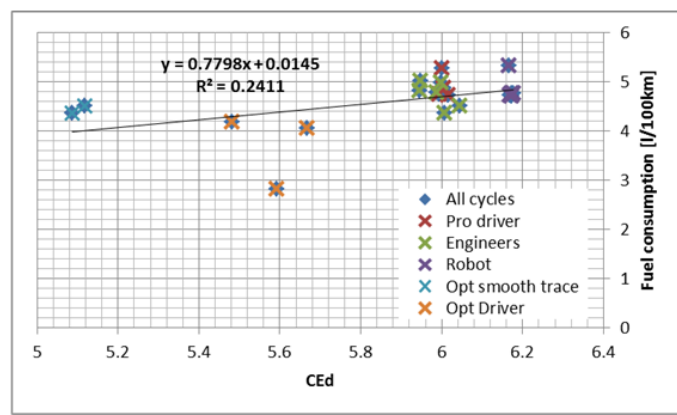

Total Cycle Energy

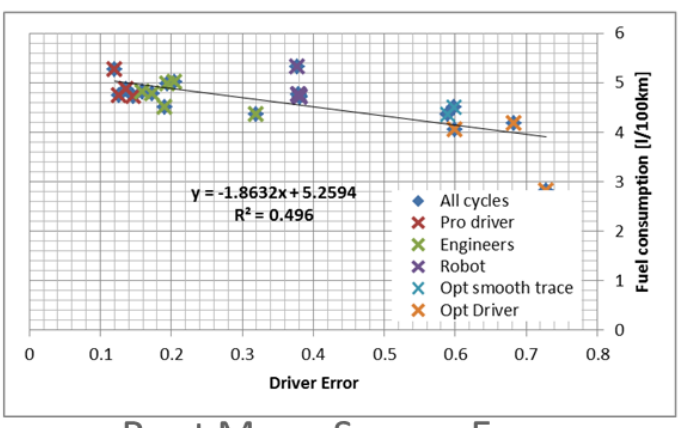

Root Mean Square Error

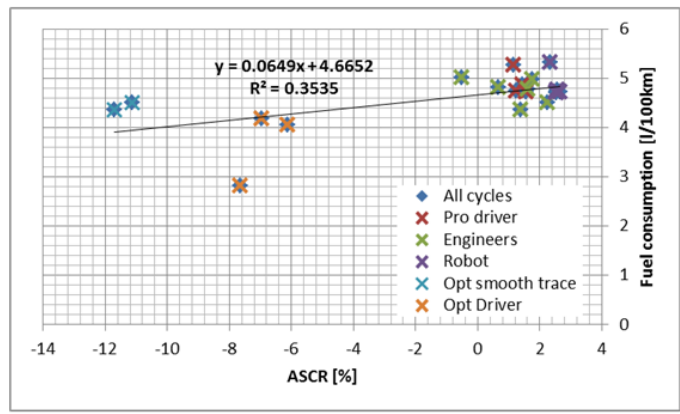

Absolute Speed Change Rating

Figure 18: A few select SAE J2951 drive quality metrics from a study comparing different drivers from professional dyno drivers to the robot driver

ANL-21/36: AMTL Vehicle Systems Instrumentation and Evaluation Methodology 
The data in Figure 18 clearly shows that the robot driver and the professional dynamometer drivers repeat results are closely clustered into two groups. Clearly the professional dynamometer drivers are very repeatable. It is notable that the robot and professional driver clusters are close but that they rarely overlay. Usually, the professional drivers perform better on these rating or are closer to the ideal rating compared to the robot driver. This information contributed to the decision to use the professional chassis dynamometer drivers for the drive cycle-based testing.

Finally, it is important to understand that neither SAE nor EPA has defined any targets or limits on these drive quality metrics to define "good" or valid testing versus "bad" or invalid tests. The Argonne staff uses its experience and judgement on these drive quality metrics to determine if a test was "bad" which rarely occurs.

Each specific vehicle report has an appendix that contains a summary of the vehicle tests performed for the technology assessment. All the $\mathbf{2} 2951$ drive metrics are provided in the test summary table of each vehicle specific report.

\subsection{Test-to-test repeatability at Argonne's AMTL}

In previous internal research on a conventional vehicle, Argonne determined that the fuel economy test-to-test variability on a UDDS drive cycle is $0.8 \%$ on cold start and $0.6 \%$ on a hot start with a $90 \%$ confidence interval in fuel consumption terms.

The low test-to-test variability is achieved by:

(1) Keeping the vehicle mounted on the chassis dynamometer for the duration of the test period;

(2) Staying very consistent on the test plan and time of day to ensure consistent day-to-day thermal conditions;

(3) The consistency in daily operation from a small staff in one test cell (including experienced professional dyno drivers); and

(4) number of other small experimental details. Like many other test laboratories, Argonne follows a strict calibration schedule for all the measurement equipment used.

In general, the certification cycle test sequence is repeated three times to establish statistical confidence in the fuel economy results. Depending on the focus of the technology assessment work, Argonne will adjust the number of repeat tests to increase the statistical confidence as required.

\section{Conclusion}

This report was developed to provide a framework of the testing methodology used by Argonne's AMTL for vehicle testing and evaluation. For further questions regarding this process, please contact the research staff. 


\section{Acknowledgements:}

This report has been developed with funding by the National Highway Traffic Safety Administration (NHTSA), which is an agency within the U.S. Department of Transportation (DOT). Special thanks go to Seiar Zia and Joseph Bayer for their technical guidance throughout the duration of this effort. Additionally, the research staff would like to thank our sponsors at the US Department of Energy (DOE) Vehicle Technology Office (VTO) for their continued support and management of research facilities and experimental efforts.

Finally, the authors would like to acknowledge that this work would not have been possible without the entire team at the Center for Transportation research, with a special thanks to testing technicians Mike Kern, Geoffrey Amann, and George Tsigolis for their support during the vehicle evaluation process.

The authors appreciate the opportunity to perform this informative laboratory testing and the data analysis, and hope that the data and results may be used to document and advance research into vehicle mobility. For any questions or comments on this testing process, please reach out to the research staff at Argonne National Laboratory for further detail. 


\section{References}

1. Fuel Economy and Greenhouse Gas Exhaust Emissions of Motor Vehicles, 40 C.F.R. $\$ 600$. Referenced 2021, Available online: https://www.ecfr.gov

2. Emission Regulations for 1977 and Later Model Year New Light-Duty Vehicles and New LightDuty Trucks and New Otto-Cycle Complete Heavy-Duty Vehicles; Test Procedures, 40 C.F.R §86, subpart C. Referenced 2021, Available online: https://www.ecfr.gov

3. SAE Standard J2951_201111, Drive Quality Evaluation for Chassis Dynamometer Testing, (2011)

4. Argonne National Laboratory Downloadable Dynamometer Database $\left(D^{3}\right)$, Available online: $w$ ww.anl.gov/d3

5. Data on Cars used for Testing Fuel Economy, EPA public databases, Available online: https://www.epa.gov/compliance-and-fuel-economy-data/data-cars-used-testing-fueleconomy

6. EPA's Transportation and Air Quality Document Index System (DIS), vehicle specific search, Available online: https://iaspub.epa.gov/otaqpub/

7. SAE Standard J1263_ 201003, Road Load Measurement and Dynamometer Simulation Using Coastdown Techniques, (2010) 


\section{Argonne}

\section{Energy Systems Division}

Argonne National Laboratory

9700 South Cass Avenue, Bldg.\#362

Argonne, IL 60439

www.anl.gov

Argonne National Laboratory is a U.S. Department of Energy laboratory managed by UChicago Argonne, LLC 